\title{
Guidelines for the Diagnosis and Treatment of Chronic Functional Constipation in Korea, 2015 Revised Edition
}

\begin{abstract}
Jeong Eun Shin, ${ }^{1}$ Hye-Kyung Jung, ${ }^{2 *}$ Tae Hee Lee, ${ }^{3}$ Yunju Jo, ${ }^{4}$ Hyuk Lee, ${ }^{5}$ Kyung Ho Song, ${ }^{6}$ Sung Noh Hong, ${ }^{5}$ Hyun Chul Lim, ${ }^{7}$ Soon Jin Lee, ${ }^{8}$ Soon Sup Chung, ${ }^{9}$ Joon Seong Lee, ${ }^{3}$ Poong-Lyul Rhee, ${ }^{5}$ Kwang Jae Lee, ${ }^{10}$ Suck Chei Choi, ${ }^{11}$ Ein Soon Shin, ${ }^{12}$ and The Clinical Management Guideline Group under the Korean Society of Neurogastroenterology and Motility
\end{abstract}

${ }^{1}$ Department of Internal Medicine, Dankook University College of Medicine, Cheonan, Korea; ${ }^{2}$ Department of Internal Medicine, Ewha Womans University School of Medicine, Seoul, Korea; ${ }^{3}$ Institute for Digestive Research, Soonchunhyang University College of Medicine, Seoul, Korea; ${ }^{4}$ Division of Gastroenterology, Department of Internal Medicine, Eulji General Hospital, Eulji University School of Medicine, Seoul, Korea; ${ }^{5}$ Department of Internal Medicine, Samsung Medical Center, Sungkyunkwan University School of Medicine, Seoul, Korea; ${ }^{6}$ Division of Gastroenterology and Hepatology, Department of Internal Medicine, Konyang University Hospital, Daejeon, Korea; ${ }^{7}$ Department of Internal Medicine, Yongin Severance Hospital, Yonsei University College of Medicine, Yongin, Gyeonggi-do, Korea; ${ }^{8}$ Department of Radiology, Samsung Medical Center, Sungkyunkwan University School of Medicine, Seoul, Korea; ${ }^{9}$ Department of Surgery, Ewha Womans University School of Medicine, Seoul, Korea; ${ }^{10}$ Department of Gastroenterology, Ajou University School of Medicine, Suwon, Korea; ${ }^{11}$ Department of Internal Medicine and Digestive Disease Research Institute, Wonkwang University School of Medicine, Iksan, Korea; and ${ }^{12}$ Steering Committee for Clinical Practice Guideline, Korean Academy of Medical Science, Korea

The Korean Society of Neurogastroenterology and Motility first published guidelines for chronic constipation in 2005 and was updated in 2011. Although the guidelines were updated using evidence-based process, they lacked multidisciplinary participation and did not include a diagnostic approach for chronic constipation. This article includes guidelines for diagnosis and treatment of chronic constipation to realistically fit the situation in Korea and to be applicable to clinical practice. The guideline development was based upon the adaptation method because research evidence was limited in Korea, and an organized multidisciplinary group carried out systematical literature review and series of evidence-based evaluations. Six guidelines were selected using the Appraisal of Guidelines for Research \& Evaluation (AGREE) II process. A total 37 recommendations were adopted, including 4 concerning the definition and risk factors of chronic constipation, 8 regarding diagnoses, and 25 regarding treatments. The guidelines are intended to help primary physicians and general health professionals in clinical practice in Korea, to provide the principles of medical treatment to medical students, residents, and other healthcare professionals, and to help patients for choosing medical services based on the information. These guidelines will be updated and revised periodically to reflect new diagnostic and therapeutic methods.

(J Neurogastroenterol Motil 2016;22:383-411)

Key Words

Adaptation; Constipation; Diagnosis; Guideline; Treatment

Received: November 28, 2015 Revised: March 13, 2016 Accepted: April 3, 2016

(a) This is an Open Access article distributed under the terms of the Creative Commons Attribution Non-Commercial License (http://creativecommons. org/licenses/by-nc/4.0) which permits unrestricted non-commercial use, distribution, and reproduction in any medium, provided the original work is properly cited.

*Correspondence: Hye-Kyung Jung, MD, PhD

Department of Internal Medicine, Ewha Womans University School of Medicine, Mokdong Hospital, 1071 Anyangcheon-ro, Yangcheon-gu, Seoul 07985, Korea

Tel: +82-2-2560-2632, Fax: +82-2-2655-2076, E-mail: junghk@ewha.ac.kr 


\section{Introduction}

\section{Background}

Constipation is a common gastrointestinal disease that may result in chronic and disabling symptoms. Estimates of the prevalence of constipation range from $10 \%$ to $15 \%$ in North America. ${ }^{1}$ In the survey administered to Asians, the prevalence of chronic constipation was reported as $15-23 \%$ of female respondents and $11 \%$ of male respondents ${ }^{2,3}$ and the prevalence of self-reported constipation was $16.5 \%$ in the general population and $9.2 \%$ of 'functional constipation' according to the Rome II criteria. ${ }^{4}$ Constipation substantially affects the quality of life in that $70 \%$ of respondents feel its disruption to their day-to-day activities. ${ }^{5}$ Chronic constipation can be primary or secondary to other medical conditions, including neurological, metabolic, or endocrine diseases. Functional constipation is a chronic condition and has various constipation-related symptoms; thus, its treatment is challenging and it has a high socioeconomic burden. ${ }^{6}$

In 2005, the Korean Society of Neurogastroenterology and Motility published guidelines for chronic constipation entitled "Review: evidence-based guidelines for diagnosis and treatment: diagnostic guidelines for constipation" and "Review: evidence-based guidelines for diagnosis and treatment: therapeutic guidelines for constipation", but these were based primarily on Western guidelines and were written in the form of a narrative review. ${ }^{7.8}$ In 2011, the "Guidelines for the treatment of constipation" were updated to fit a realistic medical environment in Korea using evidence-based development of guidelines.

Since those guidelines were published, there have been several newly developed therapeutic tools, including pharmaceutical and non-pharmacologic modalities. Furthermore, the previous Korean guidelines lacked multidisciplinary participation and did not include a diagnostic approach for chronic constipation. Although the previous guidelines were introduced and promoted, a recent survey in Korea revealed that $25-48 \%$ of patients exhibited poor recognition of constipation ${ }^{10}$ and a European study reported that $28 \%$ of constipation patients were not satisfied with existing treatments. ${ }^{11}$ As most laxatives, including stimulant laxatives, are currently purchased without prescriptions in Korea, there have been concerns about abuse. For these reasons, we sought to revise the clinical guidelines to realistically fit the situation in Korea and to be applicable to clinical practice. The Guideline Steering Committee under the Korean Society of Neurogastroenterology and Motility initiated this revi- sion in May 2013.

The attributes of this revision are as follows. First, systematic search and literature reviews were performed to examine the evidence in a scientific and objective manner. Second, the development of the revised guidelines used an adaptation process involving a methodology designed to maximize the use of existing evidencebased guidelines and to fit them into the clinical situation in Korea, where research evidence has been explored less extensively. ${ }^{12}$ The development of evidence-based clinical guidelines has been increasingly recommended and recently, the ADAPTE Collaboration was organized; it has proposed principles and standardized processes to facilitate the consistent development of guidelines through this adaptation process. The development of the current guidelines used the ADAPTE process. ${ }^{13,14}$

\section{Target Population and Purpose of the Guidelines}

Adults in need of diagnosis and treatment for chronic constipation are the primary targets, and patients who are suffering from the inconvenience associated with chronic constipation are included within the target population. The guidelines analyzed recent scientific evidence with the aim of assisting clinicians and patients in making decisions under conditions where diagnosis and treatments for chronic constipation are needed. The guidelines are also intended to help primary physicians and general health professionals to make management decisions in the fields of gastroenterology, digestive surgery, and radiology. The guidelines suggest a variety of alternatives for diagnoses and treatment methods, summarize the pros and cons of each method, and provide specific guidelines with regard to the choice of the methods and the corresponding clinical situations. Furthermore, they may be used as instructional materials and provide the principles of medical treatment to medical students, residents, and other healthcare professionals. Patients will benefit because they will have more accurate expectations of the services to be offered and will be able to choose medical services based on the information, indicating that these guidelines can educate and help them communicate regarding medical services and needs.

\section{Scope of the Revised Guidelines}

As standardized recommendations that address the diagnosis and treatment of chronic constipation in a comprehensive and practical manner, these guidelines targets adults and excludes children. Because it was not possible to address all methods associated with constipation in the guidelines, we included only commonly accepted or widely used methods, and briefly introduce new treatment modalities, including medicines, that have some clinical evidence. We 
excluded controversial information that lacks scientific evidence and issues that are still embroiled in controversy from these newly revised guidelines. When necessary, experts achieved consensus using the Delphi method to settle issues lacking a clear scientific basis.

\section{Process of Updating the Chronic Constipation Guidelines}

\section{Guideline Committee}

The Steering Committee consisted of the President and executives of the Korean Society of Neurogastroenterology and Motility. The committee established guideline development strategies, appointed a committee chairperson, and appraised/approved budget related to the project. Furthermore, the committee reviewed the recommended revisions, approved/published the final version of the guidelines, and monitored the process to ensure the participation of interested parties and the independence of the editing.

The committee for constipation management guidelines included members of the clinical management guideline group under the Korean Society of Neurogastroenterology and Motility, the chairman (H.K.J.), the secretary (J.E.S.), 6 general members (Y.J.C., T.H.L., H.L., K.H.S., S.N.H., and H.C.I.), 1 methodology expert (E.S.S.), and a coordinator. In the process of guideline development, the Korean Society of Coloproctology (S.S.C.) and the Korean Society of Radiology (S.J.L.) facilitated multidisciplinary involvement. The Guideline Development and Writing Committee set detailed goals for the guidelines, carried out detailed procedures for adaptation development, and took on various tasks including searching the evidence, developing the proposed recommendations, drafting the guidelines, and revising them. At the first meeting in March 2013, the principles of guideline development, time schedules, and guideline scopes were agreed upon. There were several workshops for establishing methods for guideline development: "The use of adaptation development to establish guideline development" (May 10, 2013), "Quality evaluation of the literature according to the Appraisal of Guidelines for Research \& Evaluation (AGREE) II" (June 21, 2013), "The practical evaluation of guidelines using AGREE II" (July 19, 2013), and "Method of data extraction/evidence inventory table" (August 31, 2013). During the development process of the guidelines, there were 12 meetings of the Guideline Development Committee.

\section{Process of Adaptation Development}

\section{Characteristics}

The guideline development was based upon the adaptation method because research evidence was limited in Korea; an organized multidisciplinary group involving the Korean Society of Coloproctology and the Korean Society of Radiology carried out systematic review and series of evidence-based evaluations. In contrast with the 2011 constipation treatment guidelines, the diagnosis of chronic constipation and new medicines were added. Following the findings of recent studies, we properly adjusted the grades of recommendation. An expert methodologist (E.S.S.) from the Korean Academy of Medical Science was involved in revising the guidelines to ensure the process in a scientific and standardized manner.

\section{Clinical questions}

To determine the clinical questions that should be included in the treatment guidelines, we designed an investigation table in accordance with the "PICO" principles: $\mathrm{P}$ (population) was defined as constipation patients or clinical characteristics of constipation, I (intervention) was defined as diagnostic or therapeutic intervention, $\mathrm{C}$ (comparison) was defined as the control group, and $\mathrm{O}$ (outcome) was defined as the effectiveness of the diagnosis or treatment. We tried to include these four principles into clinical questions. After collecting investigation tables that contained clinical questions, we prioritized them through structural debates.

\section{Web search}

In July 2013, we used the following electronic databases to search for relevant information and preexisting guidelines: MEDLINE, MEDLINE Systematic Review, MEDLINE Clinical Study, OVID MEDLINE, EMBASE, the Web of Science, SCOPUS, the Cochrane Library, the National Guideline Clearinghouse, Guidelines International Network, Google Scholar, KoreaMed, MEDRIC, KISS, and Korea National Assembly Electronic Library.

The search words were constipation-related index words ("constipation" OR "dyschezia" OR "anismus" OR "dyssynergic defecation" OR "obstructive defecation") and guideline-related index words ("guideline" OR "guidelines as topic" OR "guideline adherences" OR "practice guideline" OR "practice guidelines as topic" OR "clinical guideline" OR "clinical practice guideline" OR "consensus" OR "recommendation" OR "workshop" OR their combination) (Appendix). 
The criteria for selecting preexisting guidelines were as follows: (1) evidence-based, (2) written in Korean or English, (3) published between 2002 and 2013, (4) targeted at adults aged 19 or older, (5) latest revised versions, and (6) agreed upon by experts and external review.

Exclusion criteria were as follows: (1) guidelines not made in an evidence-based manner, (2) only targeted at inpatients, (3) outdated, and (4) addressed over-the-counter drugs (Fig. 1).

The first literature selection was performed by a medical librarian (E.A.J.), who is an expert in systematic literature reviews. She performed the search process as mentioned above, organized the findings with Endnote (Endnote X7; Thomson Reuters, New York, NY, USA) and Excel (Excel 2010; Microsoft, Redmond, WA, USA), and removed duplicate documents.

A second review was performed by reviewing the titles and abstracts from the first review to select articles that satisfied both the inclusion and exclusion criteria. Then, 2 independent reviewers read selected full articles for content validity. When there was agreement between them and the article was suitable for this adaptation, the article was selected. If the 2 reviewers could not reach an agreement, a chairperson was engaged to reach consensus. Ultimately, six preexisting guidelines were selected as seed guidelines (Fig. 1).

\section{Evaluation and selection of seed guidelines}

We used AGREE II, which is an internationally recognized method for developing guidelines, to evaluate the quality of the seed guidelines for adaptation. Each seed guideline was evaluated by 2 reviewers; we provided lectures and workshops to minimize the variation in scores across reviewers and to enhance their understandings of AGREE II. For this process, we followed the KoreanAGREE II method, developed by the Steering Committee for Clinical Practice Guidelines of the Korean Academy of Medical

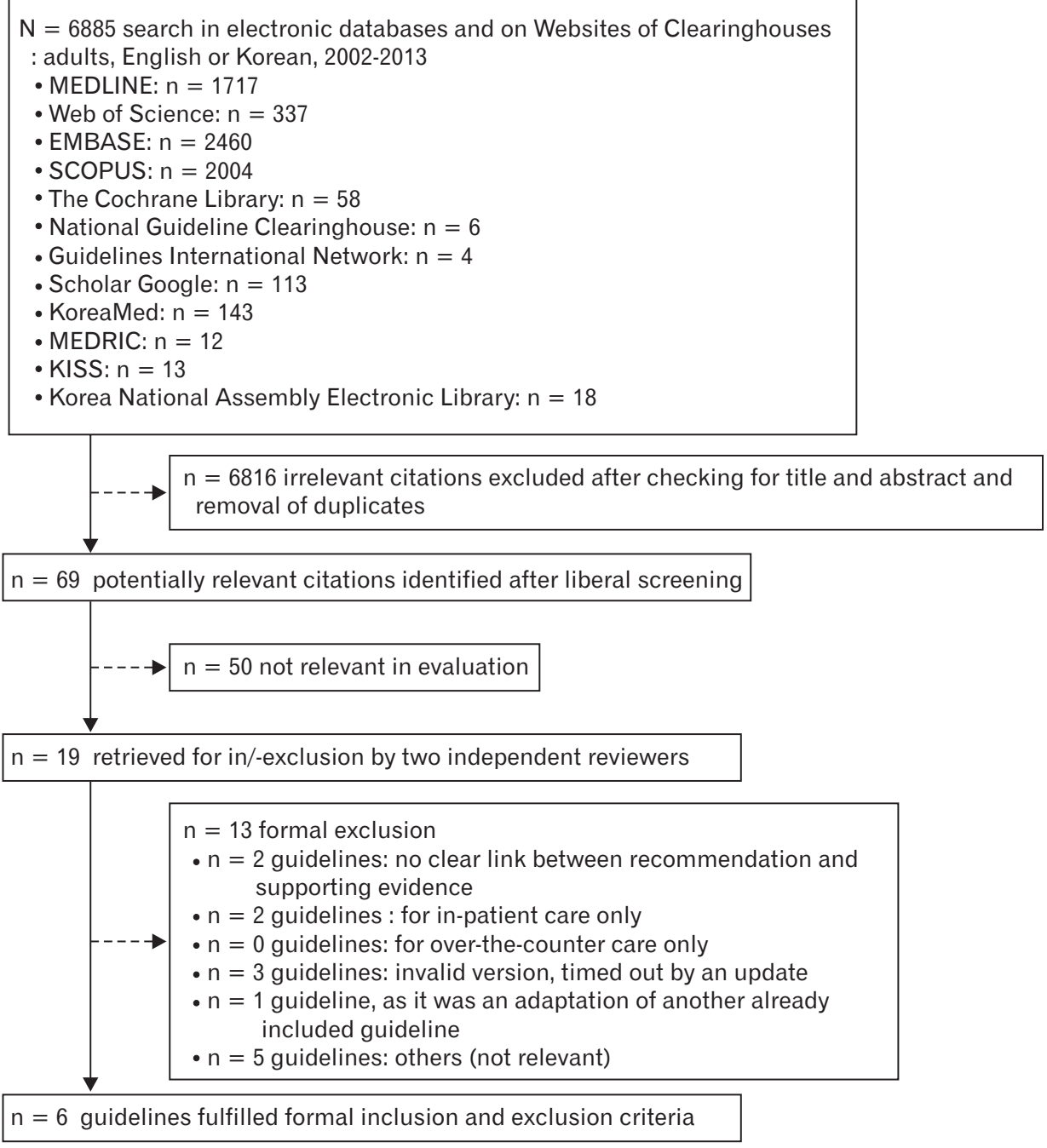

Figure 1. Flowchart of study selection. 
Sciences. The Korean-AGREE II was tested for validity through official consensus, and was shown to be valid. ${ }^{15}$ In the workshops, we selected one guideline, and all reviewers evaluated it using
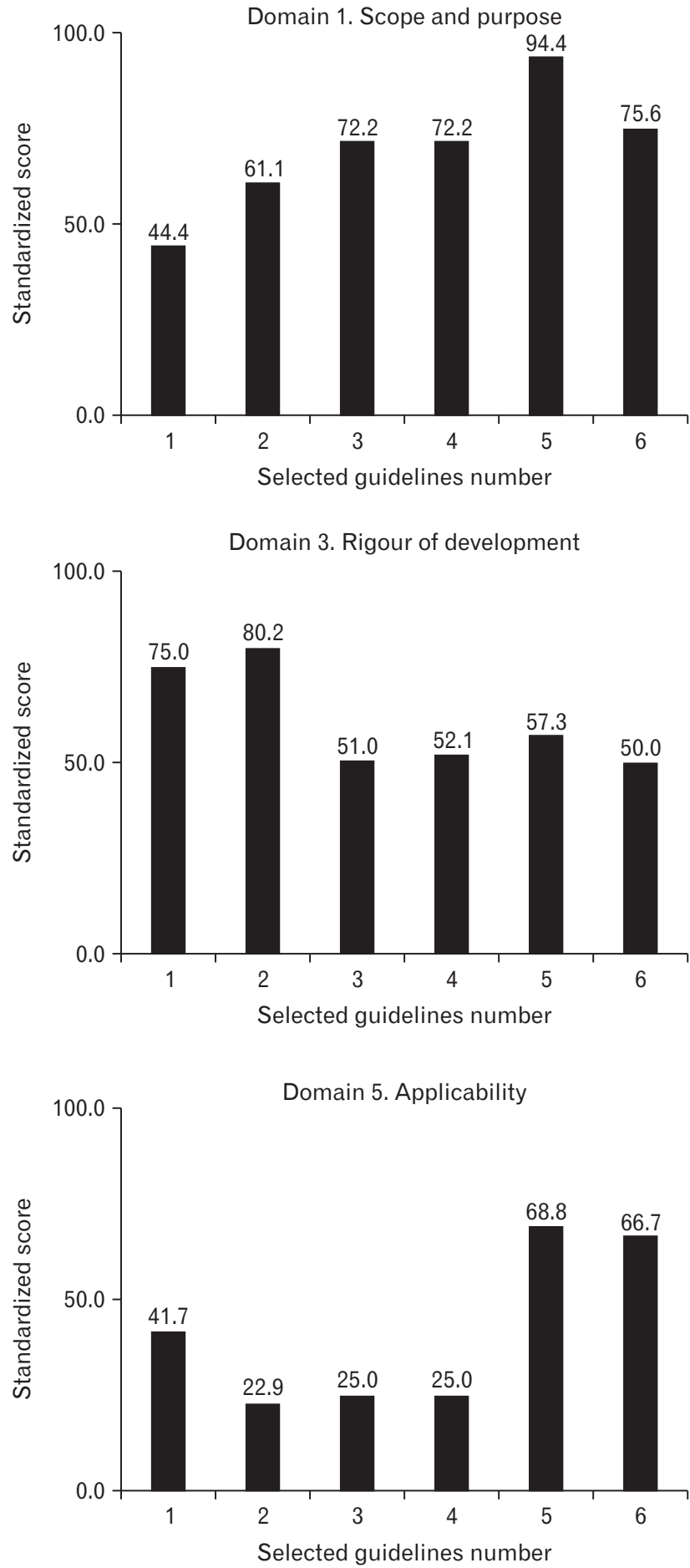

AGREE II, compared our findings with those of an experienced member for the Steering Committee for Clinical Practice Guidelines of the Korean Academy of Medical Sciences, and adjusted our
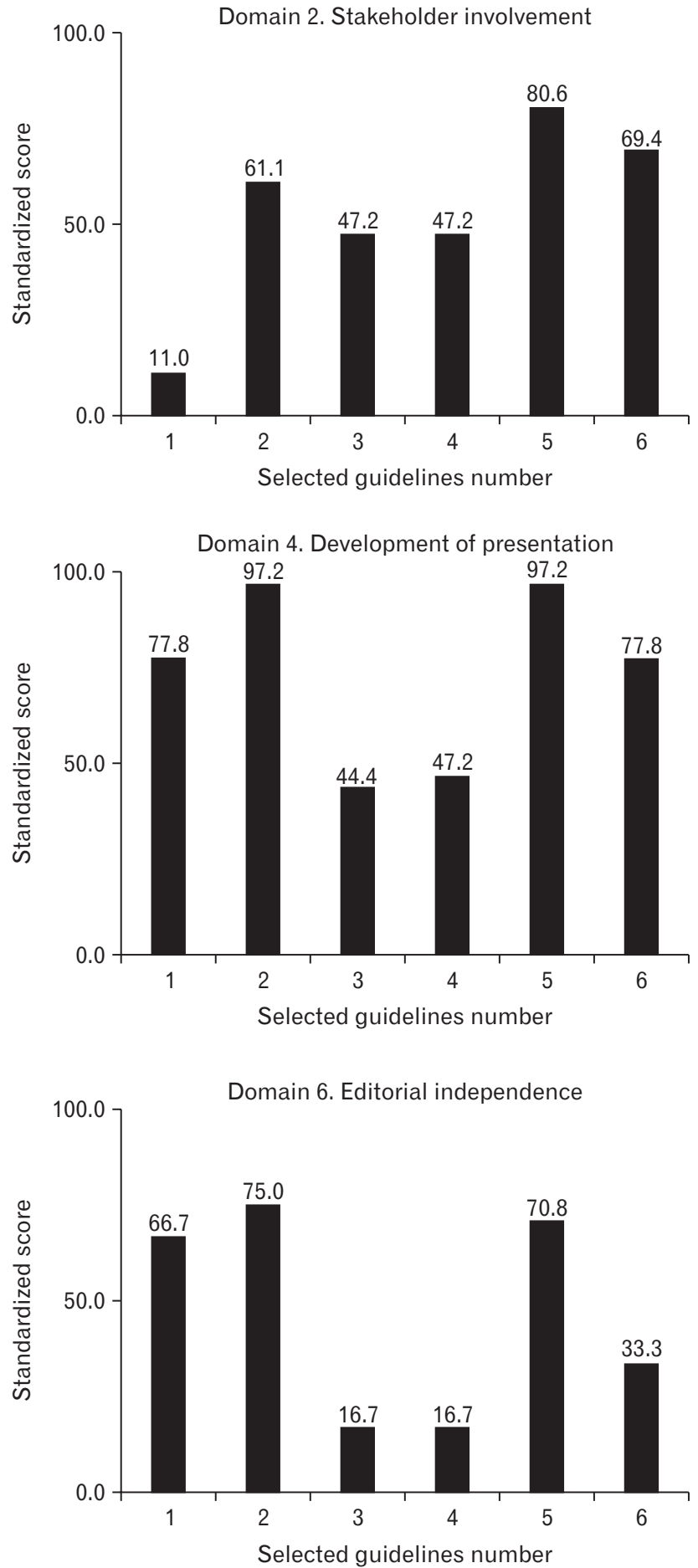

Figure 2. Appraisal results of candidate guidelines by the Appraisal of Guidelines for Research \& Evaluation (AGREE) II. Selected guidelines number: 1, Canadian recommendation; 2, Korean guideline; 3, Italian consensus for diagnosis; 4, Italian consensus for treatment; 5, American Gastroenterological Association medical position statement on constipation; and 6, American Gastroenterological Association technical review on constipation. 
findings based on the member's feedback. Two reviewers assessed each guideline, and reevaluated any guidelines for which the difference in scores was 3 points or higher on any 5 items or more. We standardized scores for each domain, created a distribution chart, and then selected 6 seed guidelines by comparing the scores in each domain (Fig. 2). We prioritized rigor of development in the selection criteria, and only selected guidelines with a rigor score of at least 50 points.

\section{Extraction of recommendations}

After selecting seed guidelines, we prepared a recommendation matrix for data extraction to extract recommendations for each subtitle based on the clinical question (PICO; Table 1). We extracted recommendations with references that best fitted the clinical questions from the selected guidelines, created a matrix based on commonly shared contents and referred articles, and developed a single set of proposed recommendations.

\section{Level of evidence and grade of recommendation}

To develop a rating system reflecting the level of evidence for each recommendation, we conducted a comprehensive quality evaluation that included the planning method, quality, and consistency

Table 1. Data Extraction Form/Evidence Inventory Form For the Effect of Bulking Agents in Chronic Constipation

\begin{tabular}{|c|c|c|c|c|c|c|c|c|}
\hline \multirow{2}{*}{ Item } & \multirow{2}{*}{ Guideline/Country/Synopsis of Recommendations } & \multicolumn{7}{|c|}{ Supporting Evidence } \\
\hline & & $\mathrm{SR} / \mathrm{MA}$ & NR & RCT & NRCS & OS & $\mathrm{CS}$ & G \\
\hline \multirow{12}{*}{$\begin{array}{l}\text { Bulking } \\
\text { agent }\end{array}$} & G1 (Canada) & 0 & 0 & 4 & 0 & 0 & 0 & 1 \\
\hline & $\begin{array}{l}\text { Psyllium is effective in the short-term treatment of chronic constipation. Studies } \\
\text { of longer duration are lacking. (Level B; agreement a: } 80 \% \text {, b: } 20 \% \text { ) }\end{array}$ & & & & & & & \\
\hline & G2 (Korea) & 0 & 0 & 5 & 0 & 0 & 0 & 1 \\
\hline & Bulking agent is effective in the treatment of chronic constipation. (Grade 1A) & & & & & & & \\
\hline & G4 (Italy) & 0 & 0 & 5 & 0 & 0 & 0 & 1 \\
\hline & The use of psyllium is supported by Level II evidence, Grade B recommendation & & & & & & & \\
\hline & G5, G6 (AGA): & 1 & 0 & 0 & 0 & 1 & 0 & 1 \\
\hline & After discontinuing medications that can cause constipation and performing & & & & & & & \\
\hline & blood and other tests as guided by clinical features, a therapeutic trial (ie, fiber & & & & & & & \\
\hline & supplementation and/or osmotic or stimulant laxatives) is recommended before & & & & & & & \\
\hline & anorectal testing (strong recommendation, moderate-quality evidence) & & & & & & & \\
\hline & $\begin{array}{l}\text { Fiber supplementation is a first step in patients with chronic constipation, parti- } \\
\text { cularly in primary care }\end{array}$ & & & & & & & \\
\hline
\end{tabular}

SR/MA, systemic review/meta-analysis; NR, nonsystematic, narrative review; RCT, randomized controlled trial; NRCS, non-randomized comparative study; OS, observational study; CS, case series study; G, guideline; AGA, American Gastroenterological Association.

Table 2. Level of Evidence and Grade of Recommendation ${ }^{16,17}$

\begin{tabular}{|c|c|}
\hline Item & Definition \\
\hline \multicolumn{2}{|l|}{ Level of evidence } \\
\hline A. High-quality evidence & $\begin{array}{l}\text { Further research is unlikely to change our confidence in the estimate of effect. Consistent evidence from the } \\
\text { RCTs without important limitations or exceptionally strong evidence from observational studies. }\end{array}$ \\
\hline B. Moderate-quality evidence & $\begin{array}{l}\text { Further research is likely to have an important impact on our confidence in the estimate of effect and may } \\
\text { change the estimate. Evidence from RCTs with important limitations (inconsistent results, methodologic } \\
\text { flaws, indirect or imprecise), or very strong evidence from observational studies. }\end{array}$ \\
\hline C. Low-quality evidence & $\begin{array}{l}\text { Further research is very likely to have an important impact on our confidence in the estimate of effect and is } \\
\text { likely to change the estimate. Evidence for at least one critical outcome from observational studies, case series, } \\
\text { or from RCTs with serious flaws, or indirect evidence, or expert's consensus. }\end{array}$ \\
\hline \multicolumn{2}{|l|}{ Strength of recommendation } \\
\hline 1. Strong recommendation & Recommendation can apply to most patients in most circumstances. \\
\hline 2. Weak recommendation & $\begin{array}{l}\text { The best action may differ depending on circumstances or patient or society values. Other alternatives may be } \\
\text { equally reasonable. }\end{array}$ \\
\hline
\end{tabular}

RCT, randomized controlled trial. 
of the study based on Grading of Recommendations Assessments, Development, and Evaluation criteria for high overall quality of evidence across outcomes; this consisted of three levels (Table 2). ${ }^{16,17}$

Recommendations were graded as either strong or weak. A strong recommendation was defined as a recommendation where positive effects are much greater than negative effects, expected effects were likely when users followed recommended instructions, and the research results were predicted not to change in the future. A weak recommendation was defined as a recommendation with inconsistent results that might not be reproducible in future studies.

\section{Expert consensus process}

For the adoption of recommendations, we structured a panel of experts that represented a group of users and specialists and used the Delphi method in the same way as for the development of updated gastroesophageal reflux disease guidelines. ${ }^{18}$

In total, 28 persons participated in the first round of Delphi consensus: 26 gastroenterologists, one surgeon from the Korean Society of Coloproctology and one expert from the Steering Committee for Clinical Practice Guidelines of the Korean Academy of Medical Sciences. The first draft included 41 recommendations: 4 concerning the definition and risk factors of chronic constipation, 8 regarding diagnoses, and 29 regarding treatments. Of the $41 \mathrm{draft}$ recommendations, 37 were selected, whereas 4 were rejected. After the second Delphi round by e-mail voting, a final total of 37 recommendations were adopted.

\section{Internal and external review methods}

The editorial supervision committee consisted of 4 members. Three (H.K.J., J.E.S., and T.H.L.) edited and proofread the first draft of the guidelines. One external expert (S.J.M.) engaged in independent peer review for verification purposes, and to enhance the balance and completeness of the guidelines.

\section{Limitations and Future Recommendations for Guideline Development}

\section{Limitations}

Developing treatment guidelines in an objective and scientific manner is challenging because evidence-based research is insufficient in Korea. However, it is not realistic to simply accept guidelines developed in other countries because these may have different medical systems and epidemiological, clinical, and ethical settings. Considering these limitations, we used adaptation methods. These evidence based guidelines were developed to help clinicians en- hance the quality of medical services and to allow patients to receive standardized and consistent clinical management. Therefore, this guideline may be different with the criteria for quality evaluation related to medical insurance.

\section{Plans for dissemination, implementation, and revision}

These revised guidelines will be accessible through the website of the Korean Society of Neurogastroenterology and Motility (http:// www.jnmjournal.org). We plan to promote the guidelines using the information center for clinical treatment guidelines established by the Korean Academy of Medical Science and will continue to promulgate them at relevant academic conferences, seminars, and workshops. These guidelines will be revised every 3-5 years to reflect new data pertaining to the development of diagnostic and therapeutic methods and the accumulation of additional research findings.

\section{Editorial independence}

As confirmed by a written pledge by participants, the development of these guidelines was made without external financial support and there were no conflict of interest for the participants involved in this research process, and it was verified by written consents.

\section{Recommended Guidelines for the Diagnosis and Treatment of Chronic Constipation}

\section{Definition of Chronic Constipation}

\section{Statement: Chronic constipation is defined as the oc- currence of bowel symptoms of infrequent bowel move- ments, hard stool, feeling of incomplete evacuation, straining at defecation, a sense of anorectal blockage during defecation, and use of digital maneuvers to assist defecation. \\ - Grade of recommendation: not applicable. \\ - Level of evidence: C. \\ - Experts' opinions: completely agree (80.8\%), mostly agree $(19.2 \%)$, partially agree $(0 \%)$, mostly disagree $(0 \%)$, com- pletely disagree $(0 \%)$, and not sure $(0 \%)$.}

Constipation is a symptom-based disorder. Physicians often regard constipation as the occurrence of infrequent bowel movements, typically fewer than three times per week, but patients have 
a broader set of symptoms, including hard stool, feeling of incomplete evacuation, and other symptoms (straining at defecation, a sense of anorectal blockage during defecation, and need for digital maneuvers to assist defecation). ${ }^{19}$ The latter symptoms suggest a defecatory disorder, even though symptoms alone do not appear to differentiate between subgroups of patients with constipation. ${ }^{20,21}$ Reduced stool frequency is poorly correlated with delayed colon transit time (CTT). ${ }^{22}$

\section{Statement: Functional constipation is classified into} three categories: defecatory disorders, slow transit constipation, and normal transit constipation.

- Grade of recommendation: not applicable.

- Level of evidence: C.

- Experts' opinions: completely agree (61.5\%), mostly agree $(34.6 \%)$, partially agree $(3.9 \%)$, mostly disagree $(0 \%)$, completely disagree $(0 \%)$, and not sure $(0 \%)$.

Constipation can be primary or secondary to other medical conditions, including neurological, metabolic, and endocrine diseases. The criteria for primary functional constipation was developed by an international group of experts. ${ }^{23}$ With respect to pathophysiology, primary functional constipation may be classified into defecatory disorders, slow transit constipation (STC), and normal transit constipation (NTC), a classification that facilitates its management. ${ }^{19,22}$

Defecatory disorders are characterized by impaired rectal evacuation because of inadequate rectal propulsion and/or increased resistance to evacuation. Obstructed defecation includes increased anal resting pressure (anismus) or lack of coordination or dyssynergia of the defecatory muscles (pelvic floor dysfunction). ${ }^{22}$ The latter may be the most likely cause, and impaired rectal sensation may also be a significant pathogenesis. ${ }^{24,25}$ Rectal hyposensitivity may coexist with structural abnormalities, such as rectocele and rectal intussusceptions. Pelvic floor dysfunction may contribute to constipation with or without delayed transit. ${ }^{26}$

STC is defined as prolonged delay in the passage of the stool through the colon. Slow transit is related to reduce colonic propulsive activity or increased uncoordinated motor activity of the colon. Motility changes in STC are occasionally related to abnormalities in the stomach and jejunum. Previous studies have demonstrated delayed gastric emptying and impaired gastric accommodation, which do not necessarily improve after colectomy for severe STC. ${ }^{27,28}$ These findings raised the possibility that STC may be a part of more global motor disorders in some cases. ${ }^{19}$

Generally, NTC is defined as a perception of constipation on the patient's self-report; however, stool movement is actually normal through the colon. NTC is associated with constipationpredominant irritable bowel syndrome (IBS-C), although there is up to a $50 \%$ overlap between IBS-C and STC. ${ }^{29}$ Abnormal results of barostat testing (reduced fasting, postprandial colonic tone or compliance) were detected in $40 \%$ of patients with NTC, $47 \%$ with STC, and $53 \%$ with defecatory disorders. ${ }^{30}$ Thus, normal or slow colonic transit is not a perfect surrogate marker for normal or abnormal colonic motor function.

\section{Risk Factors of Chronic Constipation}

\section{Statement: The physician should recommend discon- tinuing drugs that can cause constipation, if appropriate. \\ - Grade of recommendation: 1 . \\ - Level of evidence: C. \\ - Experts' opinions: completely agree (74.1\%), mostly agree (25.9\%), partially agree $(0 \%)$, mostly disagree $(0 \%)$, com- pletely disagree $(0 \%)$, and not sure $(0 \%)$.}

Careful history taking pertaining to associated disease and medication is necessary for the differential diagnosis of constipation. Organic causes of constipation include metabolic diseases (hypothyroidism, diabetes mellitus, hypercalcemia, etc), myopathy (eg, amyloidosis), neurologic diseases (Parkinson's disease, multiple sclerosis, spinal cord disease, etc), and psychological problems, including depression. One of the most common causes of constipation is medication, including anticholinergics, opioid analgesics, calcium channel blockers, antidepressants, antihistamines, antispasmodics, anticonvulsants, aluminum antacids, and iron supplements. ${ }^{31,32}$ Thus, the physician should perform careful history taking related to drugs and recommend discontinuing them, if appropriate.

\section{Statement: The prevalence of constipation in elderly populations increases because of multifactorial causes with co-morbid diseases, impaired mobility, reduced dietary fiber intake, and drugs contributing to constipation. \\ - Grade of recommendation: not applicable. \\ - Level of evidence: C. \\ - Experts' opinions: completely agree (51.9\%), mostly agree $(44.4 \%)$, partially agree $(3.7 \%)$, mostly disagree $(0 \%)$, com- pletely disagree $(0 \%)$, and not sure $(0 \%)$.}

The prevalence of constipation increases with age and is especially frequent in women. ${ }^{33,34}$ In a study by Finland, the prevalence 
of chronic constipation was $57 \%$ in elderly women and $64 \%$ in elderly men, and was more frequent in a nursing home setting: $79 \%$ in elderly women and $81 \%$ in elderly men. ${ }^{35}$ Age-related intestinal intrinsic changes may lead to constipation, but multi-factorial causes often contribute in the elderly. ${ }^{33,36}$ These causes include increased use of various prescription medications, dietary changes (poor fluid intake, low dietary fiber, a diet proportionally higher in protein and fat, or small amounts of food), impaired morbidity, and co-morbid diseases (neurological or cognitive disorders, such as Parkinson's disease, stroke, spinal cord disease, dementia, depression, etc). ${ }^{33}$

\section{Diagnosis: When Should Tests Be Performed to Assess the Causes of Chronic Constipation and When Should It Be Applied?}

\section{Bristol Stool Form Scale}

\section{Statement: Stool form may be helpful in predicting co-} lon transit time.

- Grade of recommendation: 2.

- Level of evidence: $\mathrm{C}$.

- Experts' opinions: completely agree (17.9\%), mostly agree $(57.1 \%)$, partially agree $(25.0 \%)$, mostly disagree $(0 \%)$, completely disagree $(0 \%)$, and not sure $(0 \%)$.

Stool form according to the Bristol Stool Form Scale (BSFS) is a useful visual aid (Fig. 3). ${ }^{37}$ It uses simple visual illustration that is easily understood by patients, enabling them to recognize stool form and consistency. The BSFS is a reliable indicator of $\mathrm{CTT}^{38}$ and particularly useful in patients reporting some discrepancy between the frequency of bowel movements and stool hardness. ${ }^{26}$ Some patients

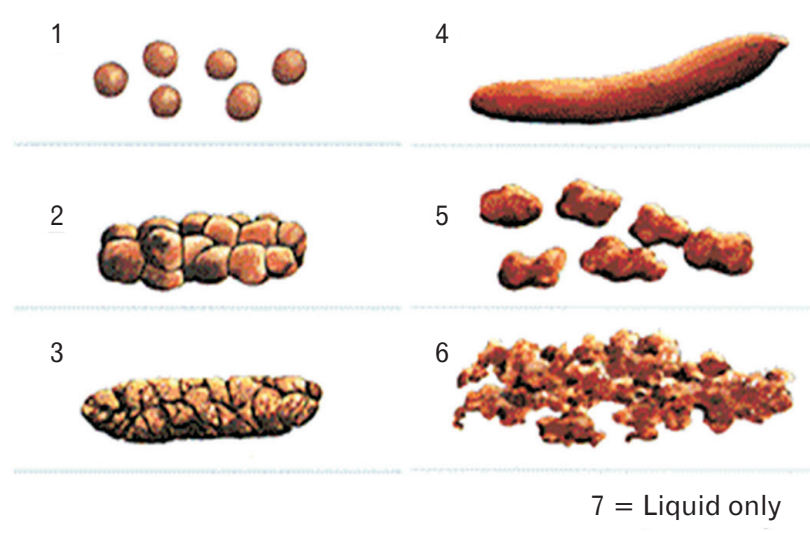

Figure 3. The Bristol Stool Form Scale. complain of having constipation with a normal frequency of bowel movement and hard or lumpy stool, but in some cases, patients consider constipation to be having rare bowel movements with normal stool consistency. No correlation has been observed between stool frequency and measured transit in constipated or healthy adults. ${ }^{38}$ In constipated adults, stool form correlated well with colon transit, but this correlation was not detected in healthy controls. Thus, history taking pertaining to stool form is a simple and useful way to estimate CTT in constipated patients.

\section{Colonoscopy}

6. Statement: Colonoscopy should be performed to exclude conditions of secondary constipation in patients with chronic constipation if the patients have alarm symptoms, such as blood in the stool, anemia, unexplained weight loss, new-onset constipation, or a family history of colon cancer

- Grade of recommendation: 1.

- Level of evidence: C.

- Experts' opinions: completely agree (85.7\%), mostly agree $(10.7 \%)$, partially agree $(3.6 \%)$, mostly disagree $(0 \%)$, completely disagree (0\%), and not sure (0\%).

Basically, testing to rule out organic disease should be left to the judgment of the treating physician, based on the constipation symptoms, the impact on the patient's quality of life, and the presence of risk factors or alarm features obtained from the history and physical examination. ${ }^{19}$ Routine extensive diagnostic testing is not recommended for chronic constipation. A systematic review noted that no reported study has assessed routine blood tests or abdominal X-rays in patients with constipation. ${ }^{39}$ A complete blood cell count can be performed. ${ }^{22}$ Although fasting serum glucose, thyroidstimulating hormone, and calcium levels are often measured, the diagnostic utility and cost-effectiveness of these tests have not been rigorously evaluated and are probably very low. ${ }^{40}$ However, colonoscopy should be performed in all patients with alarm symptoms. ${ }^{22}$ In subjects with no alarm symptoms, the rate of adenoma or colon cancer by colonoscopy has been found to be similar between groups reporting simple constipation and asymptomatic populations undergoing screening. ${ }^{39}$

Economic analysis have suggested that screening tests for colon cancer is cost-effective, ${ }^{41}$ but no formal economic analysis of the evaluation of constipation has been reported. Because patients with constipation are at similar or higher risk (newly-onset constipation 
or older age) for colon cancer, a colonoscopy is likely to also be costeffective in patients with constipation. ${ }^{42}$

\section{Statement: Colonoscopy should be performed in pa- tients with chronic constipation who have not undergone the appropriate colon cancer screening (patients $\geq 50$ years of age). \\ - Grade of recommendation: 1. \\ - Level of evidence: C. \\ - Experts' opinions: completely agree (40.7\%), mostly agree (55.6\%), partially agree $(3.7 \%)$, mostly disagree $(0 \%)$, com- pletely disagree $(0 \%)$, and not sure $(0 \%)$.}

Testing for colon cancer with colonoscopy should be considered for patients aged 50 years or older who have not undergone an ageappropriate colon cancer screening procedure since the onset of constipation. ${ }^{19,22,26,43}$ However, routine colonoscopy is not warranted for most patients with chronic constipation, because the prevalence of colonic neoplasms at colonoscopy is comparable to that in patients without chronic constipation. ${ }^{44}$

\section{Digital rectal examination}

\section{Statement: Digital rectal examination is useful for the} differential diagnosis of secondary constipation (rectoanal mass, rectal prolapse, and rectocele) and predicting defecatory disorders.

- Grade of recommendation: 1.

- Level of evidence: B.

- Experts' opinions: completely agree (29.6\%), mostly agree $(63.0 \%)$, partially agree $(3.7 \%)$, mostly disagree $(3.7 \%)$, completely disagree $(0 \%)$, and not sure $(0 \%)$.

Digital rectal examination (DRE) is an important physical examination for the diagnosis of constipation. DRE can detect stool in the rectal vault, rectoanal masses, hemorrhoids, anal fissures,

Table 3. The Methodology of Digital Rectal Examination (Adapted from Talley ${ }^{45}$ with Permission)

Techniques

1. Explain the need and method of digital rectal examination.

2. Ask the patient to lie in the left lateral position, with both knees in flexion.

3. Separate the buttocks and observe the anus and perianal area.

4. Watch the perineum.

5. Check anocutaneous reflex by light scratch with cotton bud on perianal skin.

6. Gently insert your index finger into the rectum through the anus.

7. Evaluate resting pressure of anal sphincter.

8. Rotate your finger and palpate rectal walls.

9. Test the presence of defecatory disorders.

(1) Ask the patient to simulated defecation.

(2) Press on the posterior rectal wall.

(3) Ask to simulated squeezing effort.

(4) Place your other hand on the abdominal wall and ask to strain.

10. During the finger removal, check blood, mucus, pus and feces color.
Evaluation of abnormalities such as anal cancer, rectal prolapse, external hemorrhoids, anal fissure or combined skin disease, etc.

Leakage of stool, the presence of a patulous anus, prolapse of internal hemorrhoids and rectal prolapse on straining.

If the anocutaneous reflux notably decrease, consider abnormality of sacral nerve plexus and possibility of spinal cord disease.

If the patient feels pain on starting the examination, it strongly suggests anal fissure. Other causes of anal pain include ischiorectal abscess, active proctitis, or recently thrombosed external hemorrhoids.

If the pressure is strongly high, it suggests defecatory disorders.

Evaluation of palpable mass, luminal narrowing, presence and consistency of stool in rectum, rectocele or rectal prolapse.

Normally, the anal sphincter and puborectalis muscle relax and the perineum descends by 1-3.5 $\mathrm{cm}$. If the muscles tighten and perineum does not descend, it suggests defecatory disorders.

If the patient feels pain when pressing on the posterior rectal wall, it suggests puborectalis muscle tenderness, which can occur in defecatory disorders.

Normally, puborectalis muscle contract and you feel as a "lift" that is finger lift toward the umbilicus by the muscle contraction.

Evaluation of abdominal wall contraction.

If there is persistent opening of the anal canal after finger removal, it suggests a possibility of external anal sphincter injury or neurological defect. 
rectal prolapse, and rectoceles that cause secondary constipation. ${ }^{42}$ It is also useful for identifying defecatory disorders. DRE proceeds sequentially and precisely as shown in Table $3 .^{45}$ In short, if there is inappropriate perineal descent, absence of anal sphincter relaxation or paradoxical muscle contraction, it suggests the presence of defecatory disorders. For the diagnosis of dyssynergia, a carefully performed DRE has shown $75 \%$ sensitivity and $87 \%$ specificity when conventional anorectal manometry (ARM) was adopted as the reference. ${ }^{46}$ DRE has also shown $93.2 \%$ sensitivity and $91.0 \%$ positive predictive value in detecting dyssynergia compared with high-resolution anorectal manometry (HRAM) ${ }^{47}$ DRE can be used as a bedside screening test for the diagnosis of dyssynergia and is an effective diagnostic method that enhances decisions regarding additional anorectal function tests and treatment modalities in patients with constipation. However, a normal DRE does not exclude defecatory disorders. ${ }^{22}$

\section{Anorectal manometry and balloon expulsion test}

\section{Statement: Anorectal manometry is useful for diagnos- ing defecatory disorders in patients with constipation who fail to respond to laxatives. \\ - Grade of recommendation: 1. \\ - Level of evidence: B. \\ - Experts' opinions: completely agree (50.0\%), mostly agree $(50.0 \%)$, partially agree $(0 \%)$, mostly disagree $(0 \%)$, com- pletely disagree (0\%), and not sure (0\%).}

Anorectal physiologic tests are not routinely recommended for diagnosis of chronic constipation. ${ }^{22}$ ARM is performed in patients with constipation who fail to respond to laxatives for the diagnosis of defecatory disorders. However, it may be considered earlier in cases of strongly suspected defecatory disorders. ${ }^{22,48}$ ARM includes resting anal sphincter pressure, squeezing anal sphincter pressure, rectoanal inhibitory reflex, rectal and anal pressure during attempted defecation, rectal sensation, and rectal compliance. The main finding of a defecatory disorder is absent or inadequate relaxation or paradoxical contraction of the anal sphincter during straining, sometimes associated with absent or inadequate increase of rectal pressure. ARM results should be interpreted carefully because the methods of ARM have not yet been standardized, and the results may differ according to measuring methods and equipment in each center. HRAM is generally correlated with traditional ARM. ${ }^{49}$ ARM is useful for diagnosing defecatory disorders in patients with constipation, but there is no gold standard for the diagnosis, and ab- normal results may occur in the asymptomatic general population. Thus, a comprehensive evaluation with other anorectal physiological tests, including balloon expulsion test (BET), imaging techniques, and perhaps electromyography, is necessary for diagnosing defecatory disorders. ${ }^{2}$

10. Statement: Balloon expulsion tests may be helpful in predicting defecatory disorders, but other rectoanal physiological tests should be performed to confirm the diagnosis.

- Grade of recommendation: 2.

- Level of evidence: C.

- Experts' opinions: completely agree (24.1\%), mostly agree (72.4\%), partially agree $(0 \%)$, mostly disagree $(3.5 \%)$, completely disagree $(0 \%)$, and not sure $(0 \%)$.

The BET evaluates defecatory function during a simulated defecation and can identify patients with abnormal defecation. It is a simple and inexpensive test. However, it is not supported by placebo-controlled trials and has not yet been standardized. In recent studies, a "normal" result is defined as balloon expulsion within 1 minute after attempted defecation. ${ }^{48}$ If the balloon is not expelled, it suggests the possibility of defecatory disorders. In one study, BET was $87.5 \%$ sensitive and $89 \%$ specific with positive and negative predictive values of $64 \%$ and $97 \%$ for the diagnosis of defecatory disorders, respectively. ${ }^{50}$ It was concluded that a negative test was useful for identifying patients who do not have dyssynergia. However, Rao et al $\mathrm{al}^{39,51}$ found that many patients with dyssynergia could expel the balloon, and they expressed the view that a normal test could not exclude the possibility of a defecatory disorder. BET can be helpful in predicting defecatory disorders, but other rectoanal function tests should be performed to confirm a diagnosis. ${ }^{43}$

\section{Defecography}

11. Statement: Defecography is useful for detecting anatomical abnormalities and paradoxical contraction of the pelvic floor when defecatory disorders are suspected in patients with chronic constipation.

- Grade of recommendation: 1.

- Level of evidence: B.

- Experts' opinions: completely agree (42.9\%), mostly agree (53.6\%), partially agree (3.5\%), mostly disagree (0\%), completely disagree $(0 \%)$, and not sure ( $0 \%)$.

Defecography is a type of radiological imaging in which the 
mechanism of a patient's defecation is visualized in real time using a fluoroscope. The anatomy and function of the anorectum and pelvic floor are studied dynamically at various stages during defecation. Thus, defecography is considered after inconclusive results of ARM and rectal balloon expulsion in chronic constipation with an inadequate response of therapeutic trials. ${ }^{42}$ Defecography is particularly useful for identifying anatomical abnormalities, such as paradoxical contraction of the puborectalis muscle, a rectocele, rectoanal intussusception, and complete external rectal prolapse that may be amenable to surgical intervention. ${ }^{23,52-56}$

Barium defecography is commonly used, although the test or technique is incompletely standardized and it has limited reproducibility in terms of anorectal angle measurements. ${ }^{54}$ Internal consistency of defecographic parameters has been reported to be good ( $\alpha$ $=0.78$ ), but agreements between each defecographic parameter and each test of ARM and electromyography have all been shown to be poor. ${ }^{57}$ Magnetic resonance (MR) defecography avoids radiation exposure and is better for visualizing the bony landmarks that are necessary for measuring pelvic floor motion than barium defecography. Its measurements are reproducible among observers. $^{58,59}$ However, MR defecography is an expensive test and is not commonly available at hospitals.

Endovaginal or endoanal sonography can be used to evaluate pelvic floor anatomy in patients with evacuation dysfunction. ${ }^{60}$ Endovaginal sonography is recommended as an alternative to defecography or MR imaging. ${ }^{61}$ Endoanal 3-D reconstructed sonography can provide detailed abnormalities, such as anal sphincter defects, fistulous tracts, and submucosal invasion in early anorectal cancers. $^{60}$

\section{Colon transit time}

\section{Statement: Colon transit time is useful for differentiat- ing between the subtypes of defecatory disorders and slow transit constipation in patients with chronic constipation. \\ - Grade of recommendation: 1 . \\ - Level of evidence: B. \\ - Experts' opinions: completely agree (20\%), mostly agree $(68 \%)$, partially agree (8\%), mostly disagree (4\%), completely disagree $(0 \%)$, and not sure $(0 \%)$.}

Colonic transit is most commonly and inexpensively measured using radiopaque markers. Kolomark (M.I.Tech, Pyeongtaek, Korea $^{62}$ and Sitzmarks (a capsule containing 24 markers; Konsyl Pharmaceuticals, Texas, USA) ${ }^{63}$ are commonly available markers in Korea. Several methods have been suggested and the multiple capsules technique is one of the most popular methods to measure the CTT. This technique requires the ingestion of 1 capsule a day for 3 days, followed by abdominal X-rays on day 4 and 7; a normative value for total CTT in healthy Korean adults is $22.3 \pm 16.1$ hours in males and $30.1 \pm 21.4$ hours in females. ${ }^{64}$ There are differences in CTTs by age, gender, race, and methodology. Western people and women have a longer transit time. ${ }^{62-64}$ Segmental CTT is believed to differentiate between STC and pelvic floor outlet obstruction. ${ }^{43}$ CTT can be readily performed at an early stage in the diagnostic process of chronic constipation, because CTT is easily measured in many institutions, in contrast with other tests such as ARM, defecography, or electromyography.

However, lack of standardization in the procedure makes it difficult to compare results among hospitals, ${ }^{63,65}$ and the test is less reproducible in defecatory disorders and colonic inertia. ${ }^{66}$ As more than $50 \%$ of patients with defecatory disorders show slow CTT, measurement of colon transit alone cannot exclude a defecatory disorder. Even if a defecatory disorder coexists with slow colonic transit, this finding does not alter a treatment modality such as biofeedback as the main approach for the patient. Some consider that colon transit should be performed when ARM, BET, or defecography show normal findings. ${ }^{42}$ Thus, the clinician should consider which tests are to be performed in patients with chronic constipation according to the main symptoms and the tests available at each institution.

Radiographic and scintigraphic methods correlate well, and scintigraphy requires scanning for 24 or 48 hours versus 5-7 days for completing a radiopaque marker study. ${ }^{67}$ In patients with constipation, the correlation between colonic transit by using radiopaque markers and the wireless motility-pH capsule is reasonable (correlation coefficient $=0.7){ }^{68}$

\section{Management of Chronic Constipation}

\section{Physical activity}

13. Statement: A low level of physical activity is associated with chronic constipation.

- Grade of recommendation: 2.

- Level of evidence: C.

- Experts' opinions: completely agree (7.1\%), mostly agree (67.9\%), partially agree (14.3\%), mostly disagree (10.7\%), completely disagree $(0 \%)$, and not sure $(0 \%)$. 
Data regarding the effectiveness of physcial activity in alleviating constipation have been variable. In a large survey conducted with 39,532 women, the odds ratio for constipation among women who reported lower to moderate physical activity was significantly lower than that among sedentary women in all three aged cohorts (young, middle aged, and older). Compared with sedentary young, middle aged, and older women, those with moderate physical activity showed significant odds ratios $(0.70,0.75$, and 0.82 , respectively). ${ }^{69}$ Another survey showed that constipation in elderly patients was most clearly associated with poor mobility. ${ }^{70}$ Elderly patients were thought to have an increased risk of constipation depending on their level of activity. ${ }^{35}$ More frequent bowel movements may be caused by running. ${ }^{71}$ These findings suggest that low-to-moderate levels of exercise are associated with benefits for constipated patients. A study of colonic motility using a solid state manometric probe showed that colon phasic activity was decreased during exercise and propagated activity was enhanced after exercise. ${ }^{72}$ A Korean study showed that moderate or high levels of physical activity shortened CTT in females, but not in males. ${ }^{73}$

However, the average of total physical activities was not significantly different in normally active subjects with and without constipation. ${ }^{74}$ The effect of moderate physical exercise on bowel transit time has been questioned in healthy subjects. ${ }^{75-78}$ In a small group of chronically constipated patients who did an extra hour of exercise 5 days per week for 4 weeks, there was no improvement in the number or consistency of their bowel movements or the degree of straining required for defecation. ${ }^{79}$ Increased physical activity might offer symptomatic improvement, especially in elderly constipated patients with low levels of physical activity. It is not clear that exercise helps younger constipated patients with normal activity. Recently, moderate-to-vigorous intensity physical activity (20-60 minutes, 3-5 days per week) has been shown to improve symptoms and quality of life in IBS. ${ }^{80}$ Taken together, increased physical activity should still be recommended to patients because it improves quality of life and has other health benefits unrelated to chronic constipation.

\section{Dietary fiber}

\section{Statement: Dietary fiber can increase stool frequency} in patients with chronic constipation.

- Grade of recommendation: 2.

- Level of evidence: C.

- Experts' opinions: completely agree (27.6\%), mostly agree (72.4\%), partially agree $(0 \%)$, mostly disagree $(0 \%)$, completely disagree $(0 \%)$, and not sure $(0 \%)$.
Dietary fiber undergoes parital or total fermentation in the distal small bowel and colon, leading to the production of short-chain fatty acids and gas, thereby affecting gastrointestinal function and sensation. ${ }^{81}$ A prospective cohort study showed that higher daily fiber intake significantly reduced the likelihood of self-reported constipation. ${ }^{82} \mathrm{~A}$ recent meta-analysis concluded that dietary fiber intake can clearly increase stool frequency in patients with constipation. ${ }^{83}$ Naturally occurring fiber types include soluble highly fermentable oligosaccharides (eg, fructo-oligosaccharides and galactooligosaccharides), soluble highly fermentable fiber (eg, resistant starch, pectin, guar gum), intermediate soluble fermentable fiber (eg, psyllium and oats), insoluble slowly fermentable fiber (eg, wheat bran, fruit, and vegetables), and insoluble non-fermentable fiber (eg, cellulose and sterculia). ${ }^{81}$ Good laxative effects were observed in intermediate soluble fermentable fibers, insoluble slowly fermentable fibers, and insoluble non-fermentable fibers. ${ }^{81} \mathrm{~A}$ recent study showed that treatment with dried plums resulted in a significant increase in the number of complete spontaneous bowel movements (CSBMs) and stool consistency, compared with treatment with psyllium. ${ }^{84}$

However, it is not clear that dietary fiber improves stool consistency, treatment success, laxative use, or painful defecation. ${ }^{83}$

15. Statement: Dietary fiber intake is an initial strategy in the management of chronic constipation because it has some benefits, is easy to implement, is low cost, and there is little risk of serious adverse events.

- Grade of recommendation: 2.

- Level of evidence: C.

- Experts' opinions: completely agree (35.7\%), mostly agree $(60.7 \%)$, partially agree $(3.6 \%)$, mostly disagree $(0 \%)$, completely disagree $(0 \%)$, and not sure $(0 \%)$.

Dietary fiber appears to be effective in relieving mild to moderate, but not severe constipation. ${ }^{85}$ Two Korean studies reported that dietary fiber is effective in the management of constipation without adverse events. ${ }^{86,87}$ Increased dietary fiber intakes for adults with chronic constipation is associated with considerable cost savings, potentially exceeding $\$ 12$ billion in the US population. ${ }^{88}$ There is a lack of evidence supporting the notion that dietary fiber is effective for individual constipation subtypes (obstructive, metabolic, neurological, diet-related, myogenic, drug-related, and pelvic floor dysfunction) $)^{81}$ Occasionally, patients will experience marked worsening of their constipation-related symptoms with fibers. When this occurs, severe STC or defecatory disorders should be strongly 
considered. ${ }^{89}$ It is reasonable to prescribe osmotic laxatives to avoid cramping abdominal pain before initiating an increase in dietary fiber, especially in patients with significant fecal stasis. ${ }^{81}$

\section{Bulking agents}

\section{Statement: Bulking agents are effective in the treat-} ment of chronic constipation.

- Grade of recommendation: 1.

- Level of evidence: A.

- Experts' opinions: completely agree (70.4\%), mostly agree (29.6\%), partially agree (0\%), mostly disagree (0\%), completely disagree $(0 \%)$, and not sure $(0 \%)$.

Bulking agents are fiber supplements including psyllium (ispaghula husks), calcium polycarbophil, methylcelluolose, and bran. Among them, psyllium has the highest level of evidence with regard to the treatment of chronic constipation. Compared with placebo, bulking agents (especially psyllium) resulted in improvements in global symptoms, straining, pain on defecation, and stool consistency, an increase in the mean number of stools per week, and a reduction in the number of days between stools. ${ }^{90} \mathrm{~A}$ randomized crossover study of 4 weeks treatment with psyllium showed that stool frequency, weight, consistency, and pain on defecation improved significantly on psyllium; however no effect was observed with respect to colon transit or ARM parameters. ${ }^{91}$ A single-blind, randomized, crossover study of 4 weeks treatment with psyllium improved gut transit time significantly in constipated patients with pelvic floor dysynergia, compared with a placebo group. ${ }^{92}$ However, there was no significant differences in stool frequency, consistency, or weight between the groups. In a randomized, double-blind, parallel study of 170 constipated patients, treatment with psyllium for 2 weeks significantly improved stool weight and freqeuncy (in treatment week 2), compared with docusate. ${ }^{93}$ Evidence from nine studies $^{91-99}$ of psyllium showed that it apparently improved stool frequency, but there were conflicting results regarding stool consistency and transit time. No signficant difference in advese events was observed between the psyllium group and the comparison group. However, the duration of treatment with psyllium in these studies was less than 8 weeks, although the therapeutic effect would be expected to be maintained for a long time.

Potential adverse effects of bulking agents include gas, bloating, esophageal obstruction, colonic obstruction, and calcium and iron malabsorption. There is a relative lack of data available for making a recommendation for calcium polycarbophil. Some patients tend to prefer calcium polycarbophil to psyllium with respect to bloating. ${ }^{100}$ Studies of methylcellulose and bran were lacking appropriate controls and were of low methodological quality. ${ }^{100}$

17. Statement: Bulking agents can be effective in the treatment of constipated patients with inadequate fiber intake.

- Grade of recommendation: 2.

- Level of evidence: C.

- Experts' opinions: completely agree (15.4\%), mostly agree $(80.8 \%)$, partially agree $(3.8 \%)$, mostly disagree $(0 \%)$, completely disagree $(0 \%)$, and not sure $(0 \%)$.

Inadequate intake of dietary fiber is believed to contribute to constipation, and many guidelines recommend that increasing dietary fiber intake should be the first-line step in the management of constipation. ${ }^{9,22}$ Despite the limited evidence for the benefits of this approach in constipated patients with inadequate fiber intake, a bulking agent can be effective in their symptomatic improvement. However, psyllium is not effective in severe STC or defecatory disorders. The use of osmotic laxatives may be favored before initiating treatment of bulking agents to avoid abdominal discomfort, bloating, and pain in a subset of constipated patients. ${ }^{81}$

\section{Statement: When bulking agents are used, adequate intake of fluid is recommended. \\ - Grade of recommendation: 1 . \\ - Level of evidence: C. \\ - Experts' opinions: completely agree (37.0\%), mostly agree $(55.6 \%)$, partially agree $(7.4 \%)$, mostly disagree $(0 \%)$, com- pletely disagree $(0 \%)$, and not sure $(0 \%)$.}

Contraindications for bulking agents include hypersensitivity to any included components, fecal impaction, and bowel obstruction. When bulking agents are used, inadequate fluid intake can result in abdominal gas or bloating, which may then paradoxically predispose the patient to bowel obstruction. ${ }^{101}$ The elderly in particular may have insufficient fluid intake, which may predispose them to fecal impaction and bowel obstruction. Fluid intake alone has not been reported to be effective as a treatment for constipation, ${ }^{102}$ but it may benefit patients who are dehydrated. 


\section{Magnesium salts}

\section{Statement: Magnesium salts improve stool frequency and consistency in patients with normal renal function \\ - Grade of recommendation: 1. \\ - Level of evidence: C. \\ - Experts' opinions: completely agree (57.1\%), mostly agree (39.3\%), partially agree (3.6\%), mostly disagree $(0 \%)$, com- pletely disagree $(0 \%)$, and not sure $(0 \%)$.}

Magnesium salts have been widely used in mild-to-moderate constipation because of their low price and ready availability. Only one study of 64 institutionalized older patients ( $\geq 65$ years) with chronic constipation showed that magnesium hydroxide resulted in significant improvements in bowel movements, stool consistency, and decreased use of additional laxatives, compared with a bulking agent (plantain rind) plus sorbitol. ${ }^{103}$ Polyethylene glycol (PEG) solution plus magnesium hydroxide induced more significantly effective colonic preparation in constipated patients, compared with PEG solution alone. ${ }^{104}$ In conclusion, few studies have examined the effect of magnesium hydroxide, but many clinicians believe that it improves stool frequency and consistency in patients with normal renal function.

\section{Statement: Magnesium salts result in hypermagnese-} mia in patients with impaired renal function.

- Grade of recommendation: 1.

- Level of evidence: C.

- Experts' opinions: completely agree (44.4\%), mostly agree $(51.9 \%)$, partially agree $(3.7 \%)$, mostly disagree $(0 \%)$, completely disagree $(0 \%)$, and not sure $(0 \%)$.

There are no contraindications but precautions are needed with disease-related concerns such as renal impairment or neuromuscular disease. ${ }^{105}$ Hypermagnesemia is characterized by progressive loss of neuromuscular, respiratory, and cardiovascular function. Increased magensium decreases impulse transmission across the neuromuscular junction, producing a curare-like effect. ${ }^{106} \mathrm{Car}-$ diovascular side effects of hypermagensemia include hypotension, conduction defects, bradyarrhythmia, and even cardiac arrest. ${ }^{106,107}$ Because of the risk of hypermagnesemia, magnesium salts should not be used in patients with renal impairment.

\section{Nonabsorbable carbohydrate}

\author{
21. Statement: Nonabsorbable carbohydrates improve \\ bowel frequency and stool consistency in patients with \\ chronic constipation. \\ - Grade of recommendation: 1 \\ - Level of evidence: B. \\ - Experts' opinions: completely agree (53.9\%), mostly agree \\ $(46.1 \%)$, partially agree $(0 \%)$, mostly disagree $(0 \%)$, com- \\ pletely disagree $(0 \%)$, and not sure (0\%).
}

Nonabsorbable carbohydrates, such as sorbitol and lactulose, which are classified as hyperosmolar laxatives, pass unchanged into the colon to be metabolized by colonic bacteria into lactic, acetic, and formic acids, with the liberation of carbon dioxide. These lowmolecular-weight organic acids increase intraluminal fluid osmotically. Lactulose is composed of galactose and fructose, which can be produced by the isomerization of lactose, and is a prebiotic carbohydrate that stimulates the growth of health-promoting bacteria in the human gastrointestinal tract. ${ }^{108}$ The time of onset of lactulose's effect is between 24 and 72 hours.

Early studies that were methodologically limited showed the efficacy of lactulose in improving bowel frequency and stool consistency in patients with chronic constipation. ${ }^{109,110}$ In a very early randomized trial, the success rate for lactulose was $80 \%$ and for the placebo, $33 \%$, showing a significantly different success rate. ${ }^{110}$ A 12-week, double-blind study of elderly constipated patients also revealed that reduction in the severity of symptoms, such as cramping, griping, flatulence, tenesmus, and bloating was greater with lactulose. ${ }^{109}$ Additionally, results in comparison with other laxatives, such as psyllium, sorbitol, and psyllium plus senna have been reported. ${ }^{96,111}$ In a 4-week trial, the efficacy of lactulose and ispaghula was demonstrated, and effects were similar between the two groups. Differences were demonstrated with regard to acceptability in favor of lactulose. ${ }^{96}$ When the efficacy of 4-week lactulose and $70 \%$ sorbitol were compared in a cross-over trial, there was no significant difference with regard to the percent of normal bowel movements, frequency or severity of symptoms such as bloating, cramping, and excessive flatulence, or overall health status. ${ }^{111}$

An uncontrolled trial evaluating colon transit in Korean patients suffering with functional constipation demonstrated that patients with STC showed improvements in symptoms associated with acceleration of the proximal colonic transit via lactulose. ${ }^{112}$

Because lactulose is not absorbed systemically, it is not expected 
to be associated with an increased risk of malformations in pregnant women. ${ }^{113}$ In particular, this strength can lead to the safe application of lactulose in other patients groups, including those with encephalopathy or diabetes.

\section{Statement: Long-term administration of nonabsorb-} able carbohydrate is recommended because serious adverse reactions are rare.

- Grade of recommendation: 1 .

- Level of evidence: A.

- Experts' opinions: completely agree (39.3\%), mostly agree $(60.7 \%)$, partially agree $(0 \%)$, mostly disagree $(0 \%)$, completely disagree $(0 \%)$, and not sure $(0 \%)$.

Nonabsorbable carbohydrates often cause gastrointestinal symptoms, including flatulence, intestinal cramps, nausea, and diarrhea. Although gastrointestinal side effects occur most often with lactulose due to its metabolism by colonic bacteria, these events are usually temporary. ${ }^{114}$ Considering that no potential serious side effects were found in patients treated with lactulose for more than 4 weeks, long-term treatment with this agent is generally regarded as safe and well tolerated. ${ }^{115}$

\section{Statement: Nonabsorbable carbohydrates may be ef-} fective in improving bowel frequency and constipationrelated symptoms in elderly patients with chronic constipation.

- Grade of recommendation: 2.

- Level of evidence: C.

- Experts' opinions: completely agree (10.7\%), mostly agree $(82.2 \%)$, partially agree $(7.1 \%)$, mostly disagree $(0 \%)$, completely disagree $(0 \%)$, and not sure $(0 \%)$.

Randomized controlled trials (RCTs) including elderly populations support the efficacy of lactulose for stool frequency and consistency, but many studies of the use of these nonabsorbable carbohydrates in the elderly are limited because of small sample sizes and problems with their methodologies. ${ }^{111,116,117}$

\section{Polyethylene glycol}

\author{
24. Statement : Polyethylene glycol improves bowel fre- \\ quency and stool consistency in patients with chronic con- \\ stipation. \\ - Grade of recommendation: 1. \\ - Level of evidence: A. \\ - Experts' opinions: completely agree (73.1\%), mostly agree \\ (26.9\%), partially agree $(0 \%)$, mostly disagree $(0 \%)$, com- \\ pletely disagree $(0 \%)$, and not sure $(0 \%)$.
}

PEG is a nonabsorbable and nonmetabolized polymer that draws fluid into the intestinal lumen. There is reliable evidence for the use of PEG, with several well-designed placebo-controlled randomized trials demonstrating significant benefits of PEG in improving bowel frequency and stool consistency. Numerous trials have shown both electrolyte-enriched PEG and electrolyte-free PEG to be effective in patients with chronic constipation. ${ }^{115,118-127} \mathrm{~A}$ meta-analysis concluded that PEG treatment resulted in a highly significant increase in defecations per week over placebo. ${ }^{128}$ In particular, a meta-analysis involving $10 \mathrm{RCT}$ found that PEG was better than lactulose with respect to the outcomes of stool frequency per week, form of stool, relief of abdominal pain, and the need for additional products. ${ }^{129}$ PEG is poorly absorbed systemically, and does not appear to be associated with an increased risk of malformations in pregnant women. ${ }^{130}$

\section{Statement : Long-term administration of polyethylene glycol is recommended because serious adverse reactions are rare. \\ - Grade of recommendation: 1 . \\ - Level of evidence: A. \\ - Experts' opinions: completely agree (50.0\%), mostly agree $(50.0 \%)$, partially agree $(0 \%)$, mostly disagree $(0 \%)$, com- pletely disagree $(0 \%)$, not sure $(0 \%)$.}

Long-term administration (for more than 6 months) of daily PEG was effective, and appeared to be safe, well tolerated, and devoid of significant adverse events. ${ }^{119}$ While osmotic laxatives can generally cause electrolyte disturbances, volume overload, or dehydration, and these medications should be used with caution in patients prone to renal insufficiency or cardiac abnormalities, ${ }^{131}$ PEG is considered relatively safe in these respects. Although there have been reports about common adverse events including diarrhea, ab- 
dominal pain, nausea, and vomiting, no serious adverse events have been reported with long-term PEG treatment. ${ }^{129}$

The majority of clinical guidelines, including Korean guidelines, have indicated the efficacy of PEG in patients with chronic constipation with high evidence and recommendations. ${ }^{9,19,42,132-134}$

\section{Statement : Polyethylene glycol may be effective in im-} proving bowel frequency and constipation-related symptoms in elderly patients with chronic constipation.

- Grade of recommendation: 2.

- Level of evidence: C.

- Experts' opinions: completely agree (23.1\%), mostly agree $(69.2 \%)$, partially agree $(7.7 \%)$, mostly disagree $(0 \%)$, completely disagree $(0 \%)$, and not sure $(0 \%)$.

An open-label study evaluating the safety and efficacy of PEG given in patients who were $\geq 65$ years old supported the use of PEG in elderly patients. ${ }^{135}$ In addition, a subgroup analysis of RCTs including geriatric patient groups demonstrated better efficacy of PEG than other laxatives in normalizing stool frequency and consistency. ${ }^{115}$ Although PEG can frequently cause nausea, flatulence, and diarrhea, no serious side effects were reported, and PEG was well tolerated in the elderly group.

\section{Stimulant laxatives}

27. Statement: Stimulant laxatives can be considered when bulk or osmotic laxatives are ineffective in improving bowel frequency and stool consistency in patients with chronic constipation.

- Grade of recommendation: 2.

- Level of evidence: B.

- Experts' opinions: completely agree (22.2\%), mostly agree (70.4\%), partially agree (7.4\%), mostly disagree $(0 \%)$, completely disagree $(0 \%)$, and not sure $(0 \%)$.

Stimulant laxatives represent a diverse class of agents derived primarily from anthraquinones (senna) and diphenylmethanes (bisacodyl and sodium picosulfate), and acting through direct contact with the submucosal plexus and the deeper myenteric plexus, resulting in predominantly motor but also secretory effects on the bowel. Medications including senna, cascara, bisacodyl, and sodium picosulfate are commonly used as stimulants. ${ }^{136,137}$ The onset of action of bisacodyl is 6-12 hours after oral administration and the onset of action of senna is usually $1-3$ hours.
In randomized, placebo-controlled trials of sodium picosulfate and oral bisacodyl, it was reported that these agents increased the number of CSBMs per week, improved the stool consistency, and decreased the constipation-related symptoms. ${ }^{132,138,139}$ A senna-fiber combination was more effective than lactulose in treating constipation in geriatric long-stay patients. ${ }^{116,140} \mathrm{~A}$ meta-analysis found that stimulant laxatives provided superior efficacy for chronic idiopathic constipation (relative risk, $0.54 ; 95 \%$ confidence interval $[\mathrm{CI}]$, 0.42-0.69). The number needed to treat with stimulant laxatives was 3 (95\% CI, 2.0-3.5). ${ }^{141}$ These agents are traditionally advocated for short-term use only, due to safety concerns with long-term use.

It has been reported that stimulant laxatives are associated with significant adverse events, including malabsorption, electrolyte disturbance, dose-dependent cramping, diarrhea, abuse, and development of melanosis coli. ${ }^{33,142-144}$ Cathartic colon is seen in some chronic users of stimulant laxatives, but it is unclear whether this is related to their prolonged use. ${ }^{145,146}$ Thus, stimulant laxatives may be used when patients fail to respond adequately to bulk or osmotic laxatives. ${ }^{131,144}$

Docusate, a stool softener, acts as a surfactant, allowing water to penetrate the stool mass, and increases intestinal intraluminal water and sodium secretion. Although controversy has emerged regarding its effectiveness, docusate has been used to treat and prevent constipation in geriatric and institutionalized chronically ill patients. ${ }^{147,148}$

\section{Probiotics}

28. Statement: Probiotics can be considered for use in conjunction with other drugs in the treatment of chronic constipation.

- Grade of recommendation: 2.

- Level of evidence: C.

- Experts' opinions: completely agree (14.8\%), mostly agree $(63.0 \%)$, partially agree $(18.5 \%)$, mostly disagree $(3.7 \%)$, completely disagree $(0 \%)$, and not sure $(0 \%)$.

Probiotics are defined as live microorganisms which, when administered in adequate amounts, confer a health benefit on the host. ${ }^{149}$ Previous studies have found that the intestinal microbiota in chronic constipation patients differed from that in healthy controls. ${ }^{150,151}$ A systematic review of RCTs to evaluate the efficacy and safety of probiotic supplementation for the treatment of constipation suggested a favorable effect of treatment with Bifidobacterium lactis DN-173 010, Lactobacillus casei Shirota, and Escherichia coli Nissle 1917 on defecation frequency and stool consistency. ${ }^{152}$ How- 
ever, to achieve the same health benefits seen in clinical trials, probiotics should be administered with specific strains, at a specific doses, in specific populations of people. Although the use of probiotics for the treatment of constipation may be beneficial, RCTs of probiotics in chronic constipation have potential limitations. Probiotics can be considered for use in conjunction with other drugs in the treatment of chronic constipation. ${ }^{132}$

\section{Prucalopride}

\section{Statement: Prucalopride improves stool frequency and} consistency, and reduces the need for rescue medications.

- Grade of recommendation: 1 .

- Level of evidence: A.

- Experts' opinions: completely agree (57.7\%), mostly agree $(42.3 \%)$, partially agree $(0 \%)$, mostly disagree $(0 \%)$, completely disagree $(0 \%)$, and not sure $(0 \%)$.

Prucalopride is a novel gastrointestinal prokinetic agent and acts as a high-affinity, highly selective 5-hydroxytryptamine type 4 agonist. ${ }^{132}$ Prucalopride accelerated gastrointestinal and colonic transit in constipation patients. ${ }^{153}$ Prucalopride, $2 \mathrm{mg}$ once-daily treatment over 12 weeks, was more efficacious than a placebo in improving stool frequency and stool consistency, decreasing the need for rescue medications, reducing the symptoms of constipation in Asian and non-Asian women, and was found to be safe and well-tolerated. ${ }^{154-158}$ In addition, in elderly patients, prucalopride has beneficial effects on bowel movements and constipation-associated symptoms. ${ }^{159}$ Satisfaction with bowel function was maintained for up to 18 months of treatment with prucalopride. ${ }^{160}$ Recently, prucalopride was more efficacious than placebo in improving stool frequency and life quality in men with chronic constipation, and was found to be safe and well-tolerated. ${ }^{161}$

Prucalopride is recommended at $2 \mathrm{mg}$ once daily, however the dose for the elderly ( $>65$ years) and patients with severe renal impairment (glomerular filtration rate $<30 \mathrm{~mL} / \mathrm{min} / \mathrm{m}^{2}$ ) and severe hepatic impairment (Child-Pugh class C) should start at $1 \mathrm{mg}$ once daily. Headache, nausea, abdominal pain, and diarrhea lead to discontinuation of prucalopride treatment in $\sim 5 \%$ of patients. Prucalopride is contraindicated in patients with hypersensitivity, renal impairment requiring dialysis, intestinal perforation or obstruction, and severe inflammatory conditions of the intestinal tract. ${ }^{132}$ Previous nonselective 5-hydroxytryptamine type 4 agonists (cisapride and tegaserod) have been associated with significant interactions with other receptors, leading to adverse cardiovascular events and resulting in the withdrawal of these drugs from the market. ${ }^{42}$ However, serious cardiac toxicity has not been reported in patients taking prucalopride.

Thus, when bowel symptoms are refractory to simple laxatives, prucalopride should be considered in patients with chronic constipation. If treatment with prucalopride is not effective after 4 weeks, patients should be re-examined and the benefits of continuing treatment should be reconsidered.

\section{New agents}

\section{Lubiprostone}

30. Statement: Lubiprostone improves stool frequency and stool consistency, and reduces straining.

- Grade of recommendation: not applicable.

- Level of evidence: A.

- Experts' opinions: completely agree (29.2\%), mostly agree $(58.3 \%)$, partially agree $(4.2 \%)$, mostly disagree $(0 \%)$, completely disagree $(0 \%)$, and not sure $(8.3 \%)$.

Lubiprostone is a chloride channel activator approved by the Food and Drug Administration for the treatment of chronic constipation, but is not yet available in Korea. ${ }^{132}$ Lubiprostone increases intestinal chloride secretion, accelerates transit, and facilitates ease of defecation. ${ }^{132}$ Two RCTs showed that lubiprostone, at $24 \mu \mathrm{g}$ twice daily, significantly improved stool frequency and consistency, and reduced straining. ${ }^{162,163}$ During this 48-week open-label study, lubiprostone was well tolerated. Bowel symptoms improved consistently over 48 weeks in adult patients with chronic idiopathic constipation. ${ }^{164}$ This study evaluating the efficacy of lubiprostone was, however, limited to Western subjects. Recently, lubiprostone produced a steady and effective improvement in the symptoms of chronic constipation with or without IBS in a dose-dependent manner with a good safety profile and tolerability in a Japanese population. ${ }^{165}$ The most common adverse event was nausea, and the drug may be associated with diarrhea, headache, abdominal distention, abdominal pain, flatulence, and vomiting. Lubiprostone may be considered for NTC or STC patients refractory to simple laxatives. ${ }^{42}$ 


\section{Linaclotide and bile acid transporter inhibitors}

\section{Statement: Linaclotide, a newer intestinal secreta- gogue, may be effective in constipated patients who are refractory to conventional laxatives.}

- Grade of recommendation: not applicable.

- Level of evidence: B.

- Experts' opinions: completely agree (7.2\%), mostly agree (71.4\%), partially agree (14.3\%), mostly disagree ( $0 \%)$, completely disagree (0\%), and not sure (7.1\%).

Linaclotide is a low-molecular-weight peptide having homology to the diarrhea-causing enterotoxins. Linaclotide induces efflux of chloride ions and free water into the bowel lumen by activating the apical cystic fibrosis transmembrane regulator of enterocytes. ${ }^{166}$ Linaclotide increased CSBMs in constipated patients, as demonstrated consistently in 2 large RCTs. ${ }^{167}$ The most common adverse event was diarrhea and most of the patients experienced the first episode of diarrhea during the initial 2 weeks of therapy. ${ }^{167}$

The bile acid transporter inhibitor, elobixibat, is another new agent in phase 3 trials, and is not yet available in Korea. Almost all luminal bile acid is physiologically reabsorbed thorough bile acid transporters of ileal enterocyte. If the reabsorption of bile is blocked by ileal diseases or drugs, the remnant colonic luminal bile acid causes water secretion and facilitates bowel movement. Pharmacodynamic studies showed that bile acid transporter inhibitors accelerate colonic transit and relieve constipation-related symptoms in constipated patients. ${ }^{168,169} \mathrm{~A}$ bile acid transporter inhibitor may also offer an additional benefit of improving dyslipidemia through bile acid depletion and decreased lipid absorption. ${ }^{170}$

\section{Behavioral therapy - biofeedback therapy}

\section{Statement: Biofeedback therapy is effective for treat- ing constipated patient with defecatory disorders. \\ - Grade of recommendation: 1. \\ - Level of evidence: A. \\ - Experts' opinions: completely agree (55.6\%), mostly agree (44.4\%), partially agree $(0 \%)$, mostly disagree $(0 \%)$, com- pletely disagree $(0 \%)$, and not sure $(0 \%)$.}

Biofeedback therapy is a retraining process for dyssynergic anorectal and pelvic floor muscles, which are used during defecation. This behavioral therapy employs auditory or visual presentation of anorectal and pelvic floor muscular activity through electromyography and anal manometry. The patient can perceive abnormal straining during real-time sham defection, becoming educated as to how to contract the abdominal wall and relax the pelvic floor and anal muscles. Repeated behavioral training processes can condition or retrain the patient. Eligible patients with dyssynergic patterns of defecation should be defined by ARM, or the diagnosis must be supported by one or more modalities including a BET, defecography, and CTT. ${ }^{171}$ This eligibility is supported by the fact that outcome of biofeedback therapy varies widely, depending on whether the type of constipation can be represented as isolated defecatory disorder, isolated STC, or combined type. Most (about 70\%) defecatory disorder was adequately relieved by biofeedback therapy ${ }^{172-179}$ and this favorable effect lasted for 2 years or more, as observed in long-term follow-up data, ${ }^{173,174,178,179}$ whereas only $8 \%$ of isolated STC cases were treated effectively. ${ }^{180}$ Regardless of concomitant STC, combined type patients reached satisfactory outcomes. ${ }^{172}$ Moreover, this concomitant slow transit can resolve in $65 \%$ of defecatory disorders. Thus, a detailed work-up on the type of constipation is essential before determining the indication for biofeedback therapy, and baseline diagnostic tests should define the presence of defecatory disorders, regardless of combined STC. Biofeedback therapy is believed to have little effect in isolated STC. Defecatory disorder can be treated with conventional laxatives, considering the poor availability of biofeedback therapy with respect to both experts and hardware. However, regardless of the response to conventional laxatives, it is reasonable to recommend that patients with defecatory disorders undergo biofeedback therapy.

Recently a systematic review has concluded that there is insufficient evidence to allow any firm conclusion favoring the efficacy of this behavioral therapy in the management of a chronically constipated patient. ${ }^{181}$ However, this review has also been criticized in terms of its inappropriate inclusion criteria. ${ }^{171}$ The review included constipated patients without defecatory disorder, who were therefore not actually eligible for biofeedback therapy, resulting in the inevitable dilution of the benefit of biofeedback therapy. Five RCTs have consistently concluded that biofeedback therapy is superior to controlled treatment modalities, including sham biofeedback therapy, ${ }^{180}$ diet, exercise and conventional laxatives, ${ }^{174,180} \mathrm{PEG},{ }^{182}$ diazepam, placebo medicine, ${ }^{183}$ and balloon defecation therapy. ${ }^{184}$

There are some reported factors that predict the outcome of biofeedback therapy. Harder stool consistency, shorter duration of laxative use, higher resting anal sphincter pressure, and more prolonged balloon expulsion time have been reported as predictors of a desirable outcome. ${ }^{185,186}$ Neither patient age nor gender significantly 
affect the outcome. ${ }^{186}$ The patient's willingness to participate or compliance is basically required for a behavioral therapy and seems to be one of the most important factors.

\section{Statement: Biofeedback therapy may be applied re- peatedly and safely, and can reduce the usage of laxatives. \\ - Grade of recommendation: 2. \\ - Level of evidence: C. \\ - Experts' opinions: completely agree (34.6\%), mostly agree (65.4\%), partially agree $(0 \%)$, mostly disagree $(0 \%)$, com- pletely disagree $(0 \%)$, and not sure $(0 \%)$.}

Biofeedback therapy theoretically has no harmful effect and can be applied repeatedly and safely even for aggravated patients after completion of previous sessions and for surgical candidates. The decreased use of laxatives may be one of the most important benefits that can be achieved. One controlled study showed that biofeedback therapy reduced laxative use. ${ }^{187}$ Several reports concluded that biofeedback therapy was cost-effective. ${ }^{185,188}$

\section{Sugical treatment}

\section{Statement : Colectomy can be effective in patients} with slow transit constipation and without a defecatory disorder who do not gain benefit from medical treatment.

- Grade of recommendation: 2.

- Level of evidence: C.

- Experts' opinions: completely agree (16.0\%), mostly agree (64.0\%), partially agree (16.0\%), mostly disagree (4.0\%), completely disagree $(0 \%)$, and not sure $(0 \%)$.

There are no controlled trials of surgery for patients with chronic constipation. However, surgical treatment for chronic constipation may improve constipation in patients who fail to achieve satisfaction through medical therapy. The overall rate of success documented in 39 studies involving 1423 patients was 86\% (39100\%). ${ }^{189}$ Total colectomy and ileorectal anastomosis are the most common surgical procedures for refractory constipation, and sigmoid colectomy, subtotal colectomy with ceco-rectal anastomosis, and left hemicolectomy have been used. ${ }^{189}$ Recently, laparoscopic colectomy has showed similar success rates to open surgery. ${ }^{100}$

A medical history, physical and laboratory examinations, colonoscopy, and barium enema are needed to rule out secondary causes of constipation, such as endocrine and metabolic disorders, neurologic disorders, myogenic disorders, and medications. Barium defecography and ARM studies are also required to evaluate evacuation disorders. CTT is necessary to diagnose STC for the decision of surgical treatment in constipation patients. Surgical interventions are less effective in patients who have constipation with upper gastrointestinal dysmotility, and studies including gastric emptying scan and small bowel transit time may be required. ${ }^{191}$ Surgical treatment, such as colectomy, has a limited role as a treatment option for a highly selected group of patients with STC and without defecatory disorder who have failed all non-surgical interventions, and in whom symptoms are sufficiently severe to contemplate major surgery due to serious complications and poor functional outcomes. ${ }^{192}$

\section{Statement : Surgical treatment can be effective in pa- tients who have an outlet obstruction such as symptomatic rectocele and rectal prolapse. \\ - Grade of recommendation: 2. \\ - Level of evidence: C. \\ - Experts' opinions: completely agree (19.2\%), mostly agree (61.6\%), partially agree (19.2\%), mostly disagree ( $0 \%)$, com- pletely disagree $(0 \%)$, and not sure (0\%).}

Obstructed defecation syndrome is associated with abnormalities of the pelvic organs including rectocele, rectal prolapse, and recto-anal intussusception. Surgical treatment can be an option for patients who have failed to achieve satisfaction through medical therapy, including biofeedback therapy.

Repair of the rectocele, transanal or transvaginal region, may improve obstructive defecation symptoms. ${ }^{52}$ Although surgery seems to correct anatomical defects, many side effects may occur (in approximately $50 \%$ of cases), such as constipation, fecal incontinence, incomplete bowel emptying, and sexual dysfunction. ${ }^{193}$ Surgical treatment for internal rectal prolapse is controversial and is only considered when conservative treatments fail to alleviate the patient's symptoms. ${ }^{194}$ Abdominal operations include techniques involving suspension of the prolapsed rectum with or without foreign materials, and sigmoid resection with or without rectopexy. A perineal approach and transabdominal repair (rectopexy and resection) can be used to treat rectal prolapse. ${ }^{195}$ Perineal operations include rectosigmoidectomy, Delorme's operation, mucosal plication (GantMiwa procedure), and anal encirclement (Thiersch's operation). ${ }^{196}$

The role of surgical treatment for rectal intussusception is controversial, and should be restricted to selected cases in which medical therapy has failed. Delorme's transrectal excision is an alternative procedure, and (laparoscopic) resection rectopexy is a new procedure that shows better results according to some researchers. 


\section{Local treatment - enema and suppositories}

\author{
36. Statement : Enemas can be effective in a subset of pa- \\ tients with refractory defecatory disorders. \\ - Grade of recommendation: 2. \\ - Level of evidence: C. \\ - Experts' opinions: completely agree (21.4\%), mostly agree \\ (60.7\%), partially agree (10.7\%), mostly disagree (3.6\%), \\ completely disagree $(0 \%)$, and not sure (3.6\%).
}

An enema is a popular method of treatment for constipation and has been used for hundreds of years in a variety of forms, including water, soapsuds, phosphate, and sugar solutions. Despite this long history, there is only anecdotal evidence of its value in the management of chronic constipation. Routine use is typically discouraged but may be necessary. Whereas tap water enemas seem safe for more regular use, electrolyte imbalances are more common with phosphate enemas.

However, even in the absence of strong evidence for the efficacy of an enema, many clinicians and patients find them useful and effective, both for the treatment of acute and chronic constipation, and as a means of preparing or cleansing the distal colon for endoscopic or surgical procedures. By distending the rectum, all enemas stimulate the colon to contract and eliminate the stool. Enemas may be effective in a subset of patients with obstructed defecation, and in preventing fecal impaction when chronic constipation is not intractable to medical treatment, including biofeedback therapy. ${ }^{197}$

\section{Statement: An enema should be used carefully because there are no standardized guidelines, and because it may cause complications such as rectal mucosal injury or elec- trolyte imbalance. \\ - Grade of recommendation: 2. \\ - Level of evidence: C. \\ - Experts' opinions: completely agree (42.3\%), mostly agree (38.4\%), partially agree (15.4\%), mostly disagree (0\%), com- pletely disagree (3.9\%), and not sure (0\%).}

Enemas can be effective, but their routine use is typically discouraged due to serious adverse events, such as metabolic derangement or perforation. Hypertonic sodium phosphate enemas may cause severe phosphate nephropathy, especially in the elderly with chronic renal failure. Phosphate enemas should be used with caution in patients with impaired renal function, pre-existing electrolyte imbalances, risk of electrolyte disturbance (hypocalcemia, hyperphosphatemia, or hypernatremia), and chronic inflammatory bowel disease. ${ }^{198}$ The cause of perforation in patients who underwent enemas has been reported to be the device tip, related to localized weakness of the rectal wall and obstruction. ${ }^{199}$ Because of their adverse irritating effects, resulting in rectal mucosa damage, soap enemas should be avoided.

Suppositories can help to initiate or facilitate rectal evacuation and have been used for many decades for chronic constipation in many forms, including the presumably inert but lubricating glycerin, and as stimulants, such as bisacodyl. Despite their inclusion in many 'bowel protocols' and personal testimonials of individuals, there is limited evidence to support their usefulness in the management of chronic constipation.

\section{Other non-pharmacological treatment}

\section{Sacral nerve stimulation}

Sacral nerve stimulation (SNS) may be effective in the treatment of chronic constipation when other approaches have failed. ${ }^{200}$ SNS is a surgical treatment option such that, following peripheral nerve evaluation, external electrical stimulation is delivered via a temporary lead inserted percutaneously through the third sacral foramen to the $\mathrm{S} 3$ sacral nerve. Thirteen published studies were found reporting the use of SNS for constipation. ${ }^{201}$ Ten studies involved adult subjects, including two double-blind crossover studies and three were retrospective reviews. SNS appears to be an effective treatment for constipation; however, research to date has been predominantly confined to small, low-level evidence studies with most lacking a coherent definition of constipation and SNS. Thus, it remains unclear which patients are most likely to benefit from the therapy.

\section{Extracorporeal magnetic stimulation therapy}

Extracorporeal magnetic stimulation therapy (EMST) has been reported to offer the potential for therapeutic benefit for a subset of constipated patients. ${ }^{202-204}$ EMST, which uses currentchanging magnetic fields, allows the induction of electrical stimulation in the desired deep tissue. The mechanism of EMST in the S2-S3 dermatomes for constipation is unclear. One study reported that EMST was clinically useful in STC, particularly among constipated patients with rectal hyposensitivity or the transit pattern of hindgut dysfunction. ${ }^{202}$

\section{Electrical stimulation therapy}

Electrical stimulation may be considered as an adjuvant thera- 
peutic modality for the management of constipation with rectal hyposensitivity, or among some patients refractory to biofeedback therapy. $^{205-207}$

Acknowledgements: We would like to express our sincere gratitude to Eun-Ae Jeong, PhD of the Library of Medicine of Soonchunhyang University who searched existing guidelines during the first phase of the systematic literature review. In addition, we would like to thank Prof. Seung-Jae Myung (Department of Gastroenterology, Asan Medical Center, University of Ulsan College Medicine) who reviewed the draft of this manuscript in the peer review process.

\section{Financial support: None.}

\section{Conflicts of interest: None.}

Author contributions: Jeong Eun Shin have contributed in writing and editing the paper as the first author; Jeong Eun Shin, Hye-Kyung Jung, Tae Hee Lee, Yunju Jo, Hyuk Lee, Kyung Ho Song, Sung Noh Hong, and Hyun Chul Lim have contributed in the systematic review, the extraction of recommendations, and writing the paper; Soon Jin Lee and Soon Sup Chung have contributed in the systematic review and the extraction of recommendations; Joon Seong Lee, Poong-Lyul Rhee, Kwang Jae Lee, and Suck Chei Choi supervised the manuscript; Ein Soon Shin has contributed in the development of guideline as the methodology expert; and Hye-Kyung Jung has designed the development of guideline as the chairman of the committee.

\section{References}

1. Suares NC, Ford AC. Prevalence of, and risk factors for, chronic idiopathic constipation in the community: systematic review and meta-analysis. Am J Gastroenterol 2011;106:1582-1591.

2. Wald A, Scarpignato C, Mueller-Lissner S, et al. A multinational survey of prevalence and patterns of laxative use among adults with self-defined constipation. Aliment Pharmacol Ther 2008;28:917-930.

3. Wald A, Mueller-Lissner S, Kamm MA, et al. Survey of laxative use by adults with self-defined constipation in South America and Asia: a comparison of six countries. Aliment Pharmacol Ther 2010;31:274-284.

4. Jun DW, Park HY, Lee OY, et al. A population-based study on bowel habits in a Korean community: prevalence of functional constipation and self-reported constipation. Dig Dis Sci 2006;51: 1471-1477.
5. Johanson JF, Kralstein J. Chronic constipation: a survey of the patient perspective. Aliment Pharmacol Ther 2007;25:599-608.

6. Sommers T, Corban C, Sengupta N, et al. Emergency department burden of constipation in the United States from 2006 to 2011. Am J Gastroenterol 2015;110:572-579.

7. Choi MG. Evidence based guideline for diagnosis and treatment: diagnostic guideline for constipation. Kor J Neurogastroenterol Motil 2005;11:44-50.

8. Park YS, Lee DH. Evidence based guideline for diagnosis and treatment: therapeutic guideline for constipation. Kor J Neurogastroenterol Motil 2005;11:51-57.

9. Park MI, Shin JE, Myung SJ, et al. Guidelines for the treatment of constipation. Korean J Gastroenterol 2011;57:100-114.

10. Lee TH, Choi SC, Park MI, et al. Constipation misperception is associated with gender, marital status, treatment utilization and constipation symptoms experienced. J Neurogastroenterol Motil 2014;20:379-387.

11. Müller-Lissner S, Tack J, Feng Y, Schenck F, Specht Gryp R. Levels of satisfaction with current chronic constipation treatment options in Europe - an internet survey. Aliment Pharmacol Ther 2013;37:137-145.

12. Fervers B, Remy-Stockinger M, Graham ID, et al. Guideline adaptation: an appealing alternative to de novo guideline development. Ann Intern Med 2008;148:563-564; author reply 564565.

13. Harstall C, Taenzer P, Angus DK, Moga C, Schuller T, Scott NA. Creating a multidisciplinary low back pain guideline: anatomy of a guideline adaptation process. J Eval Clin Pract 2011;17: 693-704.

14. The ADAPTE Collaboration. ADAPTE framework. 2010. http://www.g-i-n.net (accessed Jul 132010 ).

15. Steering Committee for Clinical Practice Guideline. Adaptation process for developing Korean clinical practice guideline. Seoul: Minister of Health \& Welfare, Korean Academy of Medical Science 2011.

16. Guyatt GH, Cook DJ, Jaeschke R, Pauker SG, Schünemann HJ. Grades of recommendation for antithrombotic agents: American College of Chest Physicians Evidence-Based Clinical Practice Guidelines (8th Edition). Chest 2008;133:123S-131S.

17. Schunemann HJ, Oxman AD, Brozek J, et al. Grading quality of evidence and strength of recommendations for diagnostic tests and strategies. BMJ 2008;336:1106-1110.

18. Jung HK, Hong SJ, Jo YJ, et al. Updated guidelines 2012 for gastroesophageal reflux disease. Korean J Gastroenterol 2012;60:195-218.

19. ParéP, Bridges R, Champion MC, et al. Recommendations on chronic constipation (including constipation associated with irritable bowel syndrome) treatment. Can J Gastroenterol 2007; 21(suppl B):3B-22B

20. Grotz RL, Pemberton JH, Talley NJ, Rath DM, Zinsmeister AR. Discriminant value of psychological distress, symptom profiles, and segmental colonic dysfunction in outpatients with severe 
idiopathic constipation. Gut 1994;35:798-802.

21. Glia A, Lindberg G, Nilsson LH, Mihocsa L, Akerlund JE. Clinical value of symptom assessment in patients with constipation. Dis Colon Rectum 1999;42:1401-1408.

22. Bharucha AE, Dorn SD, Lembo A, Pressman A. American Gastroenterological Association medical position statement on constipation. Gastroenterology 2013;144:211-217.

23. Bharucha AE, Wald A, Enck P, Rao S. Functional anorectal disorders. Gastroenterology 2006;130:1510-1518.

24. Rao SS, Welcher KD, Leistikow JS. Obstructive defecation: a failure of rectoanal coordination. Am J Gastroenterol 1998;93: 1042-1050.

25. Rao SS. Dyssynergic defecation. Gastroenterol Clin North Am 2001;30:97-114.

26. Tack J, Muller-Lissner S, Stanghellini V, et al. Diagnosis and treatment of chronic constipation--a European perspective. Neurogastroenterol Motil 2011;23:697-710.

27. Hemingway DM, Finlay IG. Effect of colectomy on gastric emptying in idiopathic slow-transit constipation. Br J Surg 2000;87:1193-1196.

28. Mollen RM, Hopman WP, Oyen WJ, Kuijpers HH, Edelbroek MA, Jansen JB. Effect of subtotal colectomy on gastric emptying of a solid meal in slow-transit constipation. Dis Colon Rectum 2001;44:1189-1195.

29. Prather CM. Subtypes of constipation: sorting out the confusion. Rev Gastroenterol Disord 2004;4(suppl 2):S11-S16.

30. Ravi K, Bharucha AE, Camilleri M, Rhoten D, Bakken T, Zinsmeister AR. Phenotypic variation of colonic motor functions in chronic constipation. Gastroenterology 2010;138:89-97.

31. Talley NJ, Jones M, Nuyts G, Dubois D. Risk factors for chronic constipation based on a general practice sample. Am J Gastroenterol 2003;98:1107-1111.

32. Lindberg G, Hamid SS, Malfertheiner P, et al. World Gastroenterology Organisation global guideline: constipation--a global perspective. J Clin Gastroenterol 2011;45:483-487.

33. Gallegos-Orozco JF, Foxx-Orenstein AE, Sterler SM, Stoa JM. Chronic constipation in the elderly. Am J Gastroenterol 2012; 107:18-25.

34. Higgins PD, Johanson JF. Epidemiology of constipation in North America: a systematic review. Am J Gastroenterol 2004;99:750-759.

35. Kinnunen O. Study of constipation in a geriatric hospital, day hospital, old people's home and at home. Aging (Milano) 1991; 3:161-170.

36. McCrea GL, Miaskowski C, Stotts NA, Macera L, Varma MG. Pathophysiology of constipation in the older adult. World J Gastroenterol 2008;14:2631-2638.

37. Lewis SJ, Heaton KW. Stool form scale as a useful guide to intestinal transit time. Scand J Gastroenterol 1997;32:920-924.

38. Saad RJ, Rao SS, Koch KL, et al. Do stool form and frequency correlate with whole-gut and colonic transit? Results from a multicenter study in constipated individuals and healthy controls. Am
J Gastroenterol 2010;105:403-411.

39. Rao SS, Ozturk R, Laine L. Clinical utility of diagnostic tests for constipation in adults: a systematic review. Am J Gastroenterol 2005;100:1605-1615.

40. Müller-Lissner SA, Kamm MA, Scarpignato C, Wald A. Myths and misconceptions about chronic constipation. Am J Gastroenterol 2005;100:232-242.

41. Winawer SJ, Fletcher RH, Miller L, et al. Colorectal cancer screening: clinical guidelines and rationale. Gastroenterology 1997;112:594-642.

42. Bharucha AE, Pemberton JH, Locke GR 3rd. American Gastroenterological Association technical review on constipation. Gastroenterology 2013;144:218-238.

43. Bove A, Pucciani F, Bellini M, et al. Consensus statement AIGO/SICCR: diagnosis and treatment of chronic constipation and obstructed defecation (part I: diagnosis). World J Gastroenterol 2012;18:1555-1564.

44. Schusselé Filliettaz S, Gonvers JJ, Peytremann-Bridevaux I, et al. Appropriateness of colonoscopy in Europe (EPAGE II). Functional bowel disorders: pain, constipation and bloating. Endoscopy 2009;41:234-239.

45. Talley NJ. How to do and interpret a rectal examination in gastroenterology. Am J Gastroenterol 2008;103:820-822.

46. Tantiphlachiva K, Rao P, Attaluri A, Rao SS. Digital rectal examination is a useful tool for identifying patients with dyssynergia. Clin Gastroenterol Hepatol 2010;8:955-960.

47. Soh JS, Lee HJ, Jung KW, et al. The diagnostic value of a digital rectal examination compared with high-resolution anorectal manometry in patients with chronic constipation and fecal incontinence. Am J Gastroenterol 2015;110:1197-1204.

48. Rao SS. Constipation: evaluation and treatment of colonic and anorectal motility disorders. Gastroenterol Clin North Am 2007;36:687-711.

49. Jones MP, Post J, Crowell MD. High-resolution manometry in the evaluation of anorectal disorders: a simultaneous comparison with water-perfused manometry. Am J Gastroenterol 2007;102: 850-855.

50. Minguez M, Herreros B, Sanchiz V, et al. Predictive value of the balloon expulsion test for excluding the diagnosis of pelvic floor dyssynergia in constipation. Gastroenterology 2004;126:57-62 .

51. Rao SS, Mudipalli RS, Stessman M, Zimmerman B. Investigation of the utility of colorectal function tests and Rome II criteria in dyssynergic defecation (Anismus). Neurogastroenterol Motil 2004;16:589-596.

52. Shorvon PJ, McHugh S, Diamant NE, Somers S, Stevenson GW. Defecography in normal volunteers: results and implications. Gut 1989;30:1737-1749.

53. Diamant NE, Kamm MA, Wald A, Whitehead WE. AGA technical review on anorectal testing techniques. Gastroenterology 1999;116:735-760.

54. Bharucha AE. Update of tests of colon and rectal structure and function. J Clin Gastroenterol 2006;40:96-103. 
55. Kuijpers HC, Bleijenberg G, de Morree H. The spastic pelvic floor syndrome. Large bowel outlet obstruction caused by pelvic floor dysfunction: a radiological study. Int J Colorectal Dis 1986;1:44-48.

56. Halligan S, Bartram CI, Park HJ, Kamm MA. Proctographic features of anismus. Radiology 1995;197:679-682.

57. Seong MK, Kim TW. Significance of defecographic parameters in diagnosing pelvic floor dyssynergia. J Korean Surg Soc 2013;84:225-230.

58. Bharucha AE, Fletcher JG, Seide B, Riederer SJ, Zinsmeister AR. Phenotypic variation in functional disorders of defecation. Gastroenterology 2005;128:1199-1210.

59. Reiner CS, Tutuian R, Solopova AE, Pohl D, Marincek B, Weishaupt D. MR defecography in patients with dyssynergic defecation: spectrum of imaging findings and diagnostic value. Br J Radiol 2011;84:136-144.

60. Santoro GA, Fortling B. The advantages of volume rendering in three-dimensional endosonography of the anorectum. Dis Colon Rectum 2007;50:359-368.

61. Dietz HP. Ultrasound imaging of the pelvic floor. Part I: twodimensional aspects. Ultrasound Obstet Gynecol 2004;23:80-92.

62. Kim JE, Rhee PL, Kim YH, et al. Clinical usefulness of Kolomark $^{\mathrm{TM}}$, a Korean radio-opaque marker for measuring colon transit time. Korean J Med 2001;60:337-341.

63. Metcalf AM, Phillips SF, Zinsmeister AR, MacCarty RL, Beart RW, Wolff BG. Simplified assessment of segmental colonic transit. Gastroenterology 1987;92:40-47.

64. Jung HK, Kim DY, Moon IH. Effects of gender and menstrual cycle on colonic transit time in healthy subjects. Korean J Intern Med 2003;18:181-186.

65. Hinton JM, Lennard-Jones JE, Young AC. A new method for studying gut transit times using radioopaque markers. Gut $1969 ; 10: 842-847$.

66. Nam YS, Pikarsky AJ, Wexner SD, et al. Reproducibility of colonic transit study in patients with chronic constipation. Dis Colon Rectum 2001;44:86-92.

67. Degen LP, Phillips SF. How well does stool form reflect colonic transit? Gut 1996;39:109-113.

68. Rao SS, Kuo B, McCallum RW, et al. Investigation of colonic and whole-gut transit with wireless motility capsule and radiopaque markers in constipation. Clin Gastroenterol Hepatol 2009;7:537-544.

69. Brown WJ, Mishra G, Lee C, Bauman A. Leisure time physical activity in Australian women: relationship with well being and symptoms. Res Q Exerc Sport 2000;71:206-216.

70. Donald IP, Smith RG, Cruikshank JG, Elton RA, Stoddart ME. A study of constipation in the elderly living at home. Gerontology 1985;31:112-118.

71. Sullivan SN, Wong C, Heidenheim P. Does running cause gastrointestinal symptoms? A survey of 93 randomly selected runners compared with controls. N Z Med J 1994;107:328-331.

72. Rao SS, Beaty J, Chamberlain M, Lambert PG, Gisolfi C. Ef- fects of acute graded exercise on human colonic motility. Am J Physiol 1999;276:G1221-G1226.

73. Song BK, Cho KO, Jo Y, Oh JW, Kim YS. Colon transit time according to physical activity level in adults. J Neurogastroenterol Motil 2012;18:64-69.

74. Tuteja AK, Talley NJ, Joos SK, Woehl JV, Hickam DH. Is constipation associated with decreased physical activity in normally active subjects? Am J Gastroenterol 2005;100:124-129.

75. Coenen C, Wegener M, Wedmann B, Schmidt G, Hoffmann $\mathrm{S}$. Does physical exercise influence bowel transit time in healthy young men? Am J Gastroenterol 1992;87:292-295.

76. Meshkinpour H, Kemp C, Fairshter R. Effect of aerobic exercise on mouth-to-cecum transit time. Gastroenterology 1989;96:938941.

77. Soffer EE, Summers RW, Gisolfi C. Effect of exercise on intestinal motility and transit in trained athletes. Am J Physiol 1991;260:G698-G702.

78. Bingham SA, Cummings JH. Effect of exercise and physical fitness on large intestinal function. Gastroenterology 1989;97:13891399.

79. Meshkinpour H, Selod S, Movahedi H, Nami N, James N, Wilson A. Effects of regular exercise in management of chronic idiopathic constipation. Dig Dis Sci 1998;43:2379-2383.

80. Johannesson E, Simrén M, Strid H, Bajor A, Sadik R. Physical activity improves symptoms in irritable bowel syndrome: a randomized controlled trial. Am J Gastroenterol 2011;106:915-922.

81. Eswaran S, Muir J, Chey WD. Fiber and functional gastrointestinal disorders. Am J Gastroenterol 2013;108:718-727.

82. Dukas L, Willett WC, Giovannucci EL. Association between physical activity, fiber intake, and other lifestyle variables and constipation in a study of women. Am J Gastroenterol 2003;98:17901796.

83. Yang J, Wang HP, Zhou L, Xu CF. Effect of dietary fiber on constipation: a meta analysis. World J Gastroenterol 2012;18: 7378-7383.

84. Attaluri A, Donahoe R, Valestin J, Brown K, Rao SS. Randomised clinical trial: dried plums (prunes) vs. psyllium for constipation. Aliment Pharmacol Ther 2011;33:822-828.

85. Portalatin M, Winstead N. Medical management of constipation. Clin Colon Rectal Surg 2012;25:12-19.

86. Huh JW, Park YA, Sohn SK, et al. Effect of yogurt enriched water-soluble fiber on functional constipation. J Korean Soc Coloproctol 2007;23:312-320.

87. Kim JY, Kim OY, Yoo HJ, et al. Effects of fiber supplements on functional constipation. Korean J Nutr 2006;39:35-43.

88. Schmier JK, Miller PE, Levine JA, et al. Cost savings of reduced constipation rates attributed to increased dietary fiber intakes: a decision-analytic model. BMC Public Health 2014;14:374.

89. Voderholzer WA, Schatke W, Mühldorfer BE, Klauser AG, Birkner B, Muller-Lissner SA. Clinical response to dietary fiber treatment of chronic constipation. Am J Gastroenterol 1997;92: 95-98. 
90. Suares NC, Ford AC. Systematic review: the effects of fibre in the management of chronic idiopathic constipation. Aliment Pharmacol Ther 2011;33:895-901.

91. Ashraf W, Park F, Lof J, Quigley EM. Effects of psyllium therapy on stool characteristics, colon transit and anorectal function in chronic idiopathic constipation. Aliment Pharmacol Ther 1995;9:639-647.

92. Cheskin LJ, Kamal N, Crowell MD, Schuster MM, Whitehead WE. Mechanisms of constipation in older persons and effects of fiber compared with placebo. J Am Geriatr Soc 1995;43:666669.

93. McRorie JW, Daggy BP, Morel JG, Diersing PS, Miner $\mathrm{PB}$, Robinson M. Psyllium is superior to docusate sodium for treatment of chronic constipation. Aliment Pharmacol Ther 1998;12:491-497.

94. Dettmar PW, Sykes J. A multi-centre, general practice comparison of ispaghula husk with lactulose and other laxatives in the treatment of simple constipation. Curr Med Res Opin 1998;14:227-233.

95. Fenn GC, Wilkinson PD, Lee CE, Akbar FA. A general practice study of the efficacy of Regulan in functional constipation. $\mathrm{Br}$ J Clin Pract 1986;40:192-197.

96. Rouse M, Chapman N, Mahapatra M, Grillage M, Atkinson SN, Prescott P. An open, randomised, parallel group study of lactulose versus ispaghula in the treatment of chronic constipation in adults. Br J Clin Pract 1991;45:28-30.

97. Marlett JA, Li BU, Patrow CJ, Bass P. Comparative laxation of psyllium with and without senna in an ambulatory constipated population. Am J Gastroenterol 1987;82:333-337.

98. Odes HS, Madar Z. A double-blind trial of a celandin, aloevera and psyllium laxative preparation in adult patients with constipation. Digestion 1991;49:65-71.

99. Hamilton JW, Wagner J, Burdick BB, Bass P. Clinical evaluation of methylcellulose as a bulk laxative. Dig Dis Sci 1988;33:993998.

100. Fleming V, Wade WE. A review of laxative therapies for treatment of chronic constipation in older adults. Am J Geriatr Pharmacother 2010;8:514-550.

101. Emmanuel AV, Tack J, Quigley EM, Talley NJ. Pharmacological management of constipation. Neurogastroenterol Motil 2009;21(suppl 2):41-54.

102. Young RJ, Beerman LE, Vanderhoof JA. Increasing oral fluids in chronic constipation in children. Gastroenterol Nurs 1998;21: 156-161.

103. Kinnunen O, Salokannel J. Constipation in elderly long-stay patients: its treatment by magnesium hydroxide and bulk-laxative. Ann Clin Res 1987;19:321-323.

104. Shin EK, Park SJ, Kim KJ, et al. Effect of combination pretreatment of polyethylene glycol solution and magnesium hydroxide for colonoscopy. Korean J Gastroenterol 2010;55:232-236.

105. Lexicomp Inc. Magnesium oxide: Drug information Lexicomp. 2014. http://www.uptodate.com/contents/magnesium-oxide- drug-information $?$ source $=$ search_result $\&$ search $=$ magnesium + oxide\&selectedTitle $=1 \sim 18$ (accessed 5 Dec 2014).

106. Krendel DA. Hypermagnesemia and neuromuscular transmission. Semin Neurol 1990;10:42-45.

107. Tatsumi H, Masuda Y, Imaizumi H, et al. A case of cardiopulmonary arrest caused by laxatives-induced hypermagnesemia in a patient with anorexia nervosa and chronic renal failure. J Anesth 2011;25:935-938.

108. Panesar PS, Kumari S. Lactulose: production, purification and potential applications. Biotechnol Adv 2011;29:940-948.

109. Sanders JF. Lactulose syrup assessed in a double-blind study of elderly constipated patients. J Am Geriatr Soc 1978;26:236-239.

110. Wesselius-De Casparis A, Braadbaart S, Bergh-Bohlken GE, Mimica M. Treatment of chronic constipation with lactulose syrup: results of a double-blind study. Gut 1968;9:84-86.

111. Lederle FA, Busch DL, Mattox KM, West MJ, Aske DM. Cost-effective treatment of constipation in the elderly: a randomized double-blind comparison of sorbitol and lactulose. Am J Med 1990;89:597-601.

112. Lee JS, Kim YD, Im HH, et al. The effect of lactulose on the colon transit and the various symptoms of constipation in patients with functional constipation. Korean J Neurogastroenterol Motil 2006;12:127-135.

113. Carulli N, Salvioli GF, Manenti F. Absorption of lactulose in man. Digestion 1972;6:139-145.

114. Elkington SG. Lactulose. Gut 1970;11:1043-1048.

115. Attar A, Lémann M, Ferguson A, et al. Comparison of a low dose polyethylene glycol electrolyte solution with lactulose for treatment of chronic constipation. Gut 1999;44:226-230.

116. Passmore AP, Wilson-Davies K, Stoker C, Scott ME. Chronic constipation in long stay elderly patients: a comparison of lactulose and a senna-fibre combination. BMJ 1993;307:769-771.

117. Rao SS, Go JT. Update on the management of constipation in the elderly: new treatment options. Clin Interv Aging 2010;5:163171.

118. Corazziari E, Badiali D, Habib FI, et al. Small volume isosmotic polyethylene glycol electrolyte balanced solution (PMF-100) in treatment of chronic nonorganic constipation. Dig Dis Sci 1996;41:1636-1642.

119. Corazziari E, Badiali D, Bazzocchi G, et al. Long term efficacy, safety, and tolerabilitity of low daily doses of isosmotic polyethylene glycol electrolyte balanced solution (PMF-100) in the treatment of functional chronic constipation. Gut 2000;46:522-526.

120. Dipalma JA, Cleveland MV, McGowan J, Herrera JL. A randomized, multicenter, placebo-controlled trial of polyethylene glycol laxative for chronic treatment of chronic constipation. Am J Gastroenterol 2007;102:1436-1441.

121. DiPalma JA, DeRidder PH, Orlando RC, Kolts BE, Cleveland MB. A randomized, placebo-controlled, multicenter study of the safety and efficacy of a new polyethylene glycol laxative. Am J Gastroenterol 2000;95:446-450.

122. Andorsky RI, Goldner F. Colonic lavage solution (polyethylene 
glycol electrolyte lavage solution) as a treatment for chronic constipation: a double-blind, placebo-controlled study. Am J Gastroenterol 1990;85:261-265.

123. Bassotti G, Fiorella S, Roselli P, Modesto R. Use of polyethylene glycol solution in slow transit constipation. Ital J Gastroenterol Hepatol 1999;31(suppl 3):S255-S256.

124. Cleveland MV, Flavin DP, Ruben RA, Epstein RM, Clark GE. New polyethylene glycol laxative for treatment of constipation in adults: a randomized, double-blind, placebo-controlled study. South Med J 2001;94:478-481.

125. Di Palma JA, Smith JR, Cleveland M. Overnight efficacy of polyethylene glycol laxative. Am J Gastroenterol 2002;97:17761779.

126. Freedman MD, Schwartz HJ, Roby R, Fleisher S. Tolerance and efficacy of polyethylene glycol 3350/electrolyte solution versus lactulose in relieving opiate induced constipation: a doubleblinded placebo-controlled trial. J Clin Pharmacol 1997;37:904907.

127. Chaussade S, MinićM. Comparison of efficacy and safety of two doses of two different polyethylene glycol-based laxatives in the treatment of constipation. Aliment Pharmacol Ther 2003;17:165172.

128. Belsey JD, Geraint M, Dixon TA. Systematic review and meta analysis: polyethylene glycol in adults with non-organic constipation. Int J Clin Pract 2010;64:944-955.

129. Lee-Robichaud H, Thomas K, Morgan J, Nelson RL. Lactulose versus polyethylene glycol for chronic constipation. Cochrane Database Syst Rev 2010;7:CD007570.

130. Wilkinson R. Polyethylene glycol 4000 as a continuously administered non-absorbable faecal marker for metabolic balance studies in human subjects. Gut 1971;12:654-660.

131. Lembo A, Camilleri M. Chronic constipation. N Engl J Med 2003;349:1360-1368.

132. Bove A, Bellini M, Battaglia E, et al. Consensus statement AIGO/SICCR diagnosis and treatment of chronic constipation and obstructed defecation (part II: treatment). World J Gastroenterol 2012; 18:4994-5013.

133. Gwee KA, Ghoshal UC, Gonlachanvit S, et al. Primary care management of chronic constipation in Asia: the ANMA chronic constipation tool. J Neurogastroenterol Motil 2013;19:149160.

134. Park KS, Choi SC, Park MI, et al. Practical treatments for constipation in Korea. Korean J Intern Med 2012;27:262-270.

135. Di Palma JA, Cleveland MV, McGowan J, Herrera JL. An open-label study of chronic polyethylene glycol laxative use in chronic constipation. Aliment Pharmacol Ther 2007;25:703708.

136. Ewe K. The physiological basis of laxative action. Pharmacology 1980;20(suppl 1):2-20.

137. Müller-Lissner S. Pharmacokinetic and pharmacodynamic considerations for the current chronic constipation treatments. Expert Opin Drug Metab Toxicol 2013;9:391-401.
138. Müller-Lissner S, Kamm MA, Wald A, et al. Multicenter, 4-week, double-blind, randomized, placebo-controlled trial of sodium picosulfate in patients with chronic constipation. Am J Gastroenterol 2010;105:897-903.

139. Kamm MA, Mueller-Lissner S, Wald A, Richter E, Swallow $\mathrm{R}$, Gessner U. Oral bisacodyl is effective and well-tolerated in patients with chronic constipation. Clin Gastroenterol Hepatol 2011;9:577-583.

140. Kinnunen O, Winblad I, Koistinen P, Salokannel J. Safety and efficacy of a bulk laxative containing senna versus lactulose in the treatment of chronic constipation in geriatric patients. Pharmacology 1993;47(suppl 1):253-255.

141. Ford AC, Suares NC. Effect of laxatives and pharmacological therapies in chronic idiopathic constipation: systematic review and meta-analysis. Gut 2011;60:209-218.

142. Xing JH, Soffer EE. Adverse effects of laxatives. Dis Colon Rectum 2001;44:1201-1209.

143. Badiali D, Marcheggiano A, Pallone F, et al. Melanosis of the rectum in patients with chronic constipation. Dis Colon Rectum $1985 ; 28: 241-245$.

144. Wald A. Is chronic use of stimulant laxatives harmful to the colon? J Clin Gastroenterol 2003;36:386-389.

145. Schiller LR. Constipation and fecal incontinence in the elderly. Gastroenterol Clin North Am 2001;30:497-515.

146. Joo JS, Ehrenpreis ED, Gonzalez L, et al. Alterations in colonic anatomy induced by chronic stimulant laxatives: the cathartic colon revisited. J Clin Gastroenterol 1998;26:283-286.

147. Hurdon V, Viola R, Schroder C. How useful is docusate in patients at risk for constipation? A systematic review of the evidence in the chronically ill. J Pain Symptom Manage 2000;19:130-136.

148. Tarumi Y, Wilson MP, Szafran O, Spooner GR. Randomized, double-blind, placebo-controlled trial of oral docusate in the management of constipation in hospice patients. J Pain Symptom Manage 2013;45:2-13.

149. Food and Agriculture Organization of the United Nations, World Health Organization. Guidelines for evaluation of probiotics in food: report of a joint FAO/WHO working group on drafting guidelines for the evaluation of probiotics in food. London, CA: Food and Agriculture Organization of the United Nations, World Health Organization 2002.

150. Zoppi G, Cinquetti M, Luciano A, Benini A, Muner A, Bertazzoni Minelli E. The intestinal ecosystem in chronic functional constipation. Acta Paediatr 1998;87:836-841.

151. Salminen S, Salminen E. Lactulose, lactic acid bacteria, intestinal microecology and mucosal protection. Scand J Gastroenterol Suppl 1997;222:45-48.

152. Chmielewska A, Szajewska H. Systematic review of randomised controlled trials: probiotics for functional constipation. World J Gastroenterol 2010;16:69-75.

153. Bouras EP, Camilleri M, Burton DD, Thomforde G, McKinzie S, Zinsmeister AR. Prucalopride accelerates gastrointestinal and colonic transit in patients with constipation without a rectal evacu- 
ation disorder. Gastroenterology 2001;120:354-360.

154. Camilleri M, Kerstens R, Rykx A, Vandeplassche L. A placebocontrolled trial of prucalopride for severe chronic constipation. $\mathrm{N}$ Engl J Med 2008;358:2344-2354.

155. Quigley EM, Vandeplassche L, Kerstens R, Ausma J. Clinical trial: the efficacy, impact on quality of life, and safety and tolerability of prucalopride in severe chronic constipation--a 12-week, randomized, double-blind, placebo-controlled study. Aliment Pharmacol Ther 2009;29:315-328.

156. Tack J, van Outryve M, Beyens G, Kerstens R, Vandeplassche L. Prucalopride (Resolor) in the treatment of severe chronic constipation in patients dissatisfied with laxatives. Gut 2009;58:357365.

157. Ke M, Zou D, Yuan Y, et al. Prucalopride in the treatment of chronic constipation in patients from the Asia-Pacific region: a randomized, double-blind, placebo-controlled study. Neurogastroenterol Motil 2012;24:999-1007, e1540-e1541.

158. Ke M, Tack J, Quigley EM, et al. Effect of prucalopride in the treatment of chronic constipation in Asian and non-Asian women: a pooled analysis of 4 randomized, placebo-controlled studies. J Neurogastroenterol Motil 2014;20:458-468.

159. Müller-Lissner S, Rykx A, Kerstens R, Vandeplassche L. A double-blind, placebo-controlled study of prucalopride in elderly patients with chronic constipation. Neurogastroenterol Motil 2010;22:991-998, e255.

160. Camilleri M, Van Outryve MJ, Beyens G, Kerstens R, Robinson P, Vandeplassche L. Clinical trial: the efficacy of open-label prucalopride treatment in patients with chronic constipation - followup of patients from the pivotal studies. Aliment Pharmacol Ther 2010;32:1113-1123.

161. Yiannakou Y, Piessevaux H, Bouchoucha M, et al. A randomized, double-blind, placebo-controlled, phase 3 trial to evaluate the efficacy, safety, and tolerability of prucalopride in men with chronic constipation. Am J Gastroenterol 2015;110:741-748.

162. Johanson JF, Morton D, Geenen J, Ueno R. Multicenter, 4-week, double-blind, randomized, placebo-controlled trial of lubiprostone, a locally-acting type- 2 chloride channel activator, in patients with chronic constipation. Am J Gastroenterol 2008;103:170-177.

163. Barish CF, Drossman D, Johanson JF, Ueno R. Efficacy and safety of lubiprostone in patients with chronic constipation. Dig Dis Sci 2010;5 5:1090-1097.

164. Lembo AJ, Johanson JF, Parkman HP, Rao SS, Miner PB, Jr., Ueno R. Long-term safety and effectiveness of lubiprostone, a chloride channel (ClC-2) activator, in patients with chronic idiopathic constipation. Dig Dis Sci 2011;56:2639-2645.

165. Fukudo S, Hongo M, Kaneko H, Ueno R. Efficacy and safety of oral lubiprostone in constipated patients with or without irritable bowel syndrome: a randomized, placebo-controlled and dose-finding study. Neurogastroenterol Motil 2011;23:544-550, e204-e205.

166. Bharucha AE, Waldman SA. Taking a lesson from microbial diarrheagenesis in the management of chronic constipation. Gastroenterology 2010;138:813-817.

167. Lembo AJ, Schneier HA, Shiff SJ, et al. Two randomized trials of linaclotide for chronic constipation. N Engl J Med 2011;365: 527-536.

168. Simrén M, Bajor A, Gillberg PG, Rudling M, Abrahamsson H. Randomised clinical trial: the ileal bile acid transporter inhibitor A3309 vs. placebo in patients with chronic idiopathic constipation--a double-blind study. Aliment Pharmacol Ther 2011;34:41-50.

169. Wong BS, Camilleri M, McKinzie S, Burton D, Graffner H, Zinsmeister AR. Effects of A3309, an ileal bile acid transporter inhibitor, on colonic transit and symptoms in females with functional constipation. Am J Gastroenterol 2011;106:2154-2164.

170. Wong BS, Camilleri M. Elobixibat for the treatment of constipation. Expert Opin Investig Drugs 2013;22:277-284.

171. Rao SS, Benninga MA, Bharucha AE, Chiarioni G, Di Lorenzo $\mathrm{C}$, Whitehead WE. ANMS-ESNM position paper and consensus guidelines on biofeedback therapy for anorectal disorders. Neurogastroenterol Motil 2015;27:594-609.

172. Chiarioni G, Salandini L, Whitehead WE. Biofeedback benefits only patients with outlet dysfunction, not patients with isolated slow transit constipation. Gastroenterology 2005;129:86-97.

173. Chiotakakou-Faliakou E, Kamm MA, Roy AJ, Storrie JB, Turner IC. Biofeedback provides long-term benefit for patients with intractable, slow and normal transit constipation. Gut 1998;42:517-521.

174. Rao SS, Valestin J, Brown CK, Zimmerman B, Schulze K. Long-term efficacy of biofeedback therapy for dyssynergic defecation: randomized controlled trial. Am J Gastroenterol 2010;105:890-896.

175. Jeong JH, Choi JS, Seo YJ, Kim JH. Biofeedback therapy in patients with nonrelaxing puborectalis syndrome: are there differences of therapeutic effect according to methods of diagnosis? J Korean Soc Coloproctol 2001;17:26-32.

176. Jung KW, Myung SJ, Byeon JS, et al. Response to biofeedback therapy for patients with rectal hyposensitivity. Intest Res 2008;6:56-69.

177. Myung SJ. Biofeedback therapy in constipation and fecal incontinence. J Neurogastroenterol Motil 2010;16:110-112.

178. Lee BH, Kim N, Kang SB, et al. The long-term clinical efficacy of biofeedback therapy for patients with constipation or fecal incontinence. J Neurogastroenterol Motil 2010;16:177-185.

179. Lee HJ, Boo SJ, Jung KW, et al. Long-term efficacy of biofeedback therapy in patients with dyssynergic defecation: results of a median 44 months follow-up. Neurogastroenterol Motil 2015; 27:787-795.

180. Rao SS, Seaton K, Miller M, et al. Randomized controlled trial of biofeedback, sham feedback, and standard therapy for dyssynergic defecation. Clin Gastroenterol Hepatol 2007;5:331-338.

181. Woodward S, Norton C, Chiarelli P. Biofeedback for treatment of chronic idiopathic constipation in adults. Cochrane Database 
Syst Rev 2014;3:CD008486.

182. Chiarioni G, Whitehead WE, Pezza V, Morelli A, Bassotti G. Biofeedback is superior to laxatives for normal transit constipation due to pelvic floor dyssynergia. Gastroenterology 2006;130:657664.

183. Heymen S, Scarlett Y, Jones K, Ringel Y, Drossman D, Whitehead WE. Randomized, controlled trial shows biofeedback to be superior to alternative treatments for patients with pelvic floor dyssynergia-type constipation. Dis Colon Rectum 2007;50:428441.

184. Koutsomanis D, Lennard-Jones JE, Kamm MA. Prospective study of biofeedback treatment for patients with slow and normal transit constipation. Eur J Gastroenterol Hepatol 1994;6:131137.

185. Jorge JM, Habr-Gama A, Wexner SD. Biofeedback therapy in the colon and rectal practice. Appl Psychophysiol Biofeedback 2003;28:47-61.

186. Shim LS, Jones M, Prott GM, Morris LI, Kellow JE, Malcolm A. Predictors of outcome of anorectal biofeedback therapy in patients with constipation. Aliment Pharmacol Ther 2011;33:12451251.

187. Chiarioni G, Heymen S, Whitehead WE. Biofeedback therapy for dyssynergic defecation. World J Gastroenterol 2006;12:70697074.

188. Gadel Hak N, El-Hemaly M, Hamdy E, et al. Pelvic floor dyssynergia: efficacy of biofeedback training. Arab J Gastroenterol 2011;12:15-19.

189. Arebi N, Kalli T, Howson W, Clark S, Norton C. Systematic review of abdominal surgery for chronic idiopathic constipation. Colorectal Dis 2011;13:1335-1343.

190. Conzo G, Allaria A, Stanzione F, et al. Laparoscopic treatment of chronic slow transit constipation. Report of three cases and review of literature. Ann Ital Chir 2012;83:113-117.

191. Redmond JM, Smith GW, Barofsky I, Ratych RE, Goldsborough DC, Schuster MM. Physiological tests to predict longterm outcome of total abdominal colectomy for intractable constipation. Am J Gastroenterol 1995;90:748-753.

192. FitzHarris GP, Garcia-Aguilar J, Parker SC, et al. Quality of life after subtotal colectomy for slow-transit constipation: both quality and quantity count. Dis Colon Rectum 2003;46:433-440.

193. Mellgren A, Anzen B, Nilsson BY, et al. Results of rectocele repair. A prospective study. Dis Colon Rectum 1995;38:7-13.

194. Tou S, Brown SR, Malik AI, Nelson RL. Surgery for com- plete rectal prolapse in adults. Cochrane Database Syst Rev 2008;4:CD001758.

195. Ludwig KA. Management of colorectal-anal dysfunction. Obstet Gynecol Clin North Am 1998;25:923-944.

196. Yamana T, Iwadare J. Mucosal plication (Gant-Miwa procedure) with anal encircling for rectal prolapse--a review of the Japanese experience. Dis Colon Rectum 2003;46:S94-S99.

197. Bouras EP, Tangalos EG. Chronic constipation in the elderly. Gastroenterol Clin North Am 2009;38:463-480.

198. Mendoza J, Legido J, Rubio S, Gisbert JP. Systematic review: the adverse effects of sodium phosphate enema. Aliment Pharmacol Ther 2007;26:9-20.

199. Paran H, Butnaru G, Neufeld D, Magen A, Freund U. Enema-induced perforation of the rectum in chronically constipated patients. Dis Colon Rectum 1999;42:1609-1612.

200. Pinto RA, Sands DR. Surgery and sacral nerve stimulation for constipation and fecal incontinence. Gastrointest Endosc Clin N Am 2009; 19:83-116, vi-vii.

201. Carrington EV, Evers J, Grossi U, et al. A systematic review of sacral nerve stimulation mechanisms in the treatment of fecal incontinence and constipation. Neurogastroenterol Motil 2014;26: 1222-1237.

202. Lee KJ, Kim JH, Cho SW. Short-term effects of magnetic sacral dermatome stimulation for idiopathic slow transit constipation: sham-controlled, cross-over pilot study. J Gastroenterol Hepatol 2006;21:47-53.

203. Chiu CM, Wang CP, Sung WH, Huang SF, Chiang SC, Tsai PY. Functional magnetic stimulation in constipation associated with Parkinson's disease. J Rehabil Med 2009;41:1085-1089.

204. Tsai PY, Wang CP, Chiu FY, Tsai YA, Chang YC, Chuang TY. Efficacy of functional magnetic stimulation in neurogenic bowel dysfunction after spinal cord injury. J Rehabil Med 2009;41:4147.

205. Jung KW, Yang DH, Yoon IJ, et al. Electrical stimulation therapy in chronic functional constipation: five years' experience in patients refractory to biofeedback therapy and with rectal hyposensitivity. J Neurogastroenterol Motil 2013;19:366-373.

206. Chang HS, Myung SJ, Yang SK, et al. Functional constipation with impaired rectal sensation improved by electrical stimulation therapy: report of a case. Dis Colon Rectum 2004;47:933-936.

207. Chang HS, Myung SJ, Yang SK, et al. Effect of electrical stimulation in constipated patients with impaired rectal sensation. Int J Colorectal Dis 2003;18:433-438. 
Appendix. Formulate Research Question

\begin{tabular}{|c|c|c|c|}
\hline No & Keyword & Search results & Search category \\
\hline 1 & Constipation & 19441 & $\mathrm{MeSH}$ \\
\hline 2 & Constipation & 144588 & All Fields \\
\hline 3 & Constipation & 20201 & Title Word \\
\hline 4 & Dyschezia & 52428 & All Fields \\
\hline 5 & Dyschezia & 101 & Title Word \\
\hline 6 & Colonic Inertia & 977 & All Fields \\
\hline 7 & Colonic Inertia & 350 & Title Word \\
\hline 8 & Anismus & 789 & All Fields \\
\hline 9 & Anismus & 269 & Title Word \\
\hline 10 & Dyssynergic defecation & 500 & All Fields \\
\hline 11 & Dyssynergic defecation & 215 & Title Word \\
\hline 12 & Obstructive defecation & 495 & All Fields \\
\hline 13 & Obstructive defecation & 126 & Title Word \\
\hline 14 & $\mathrm{OR} / 1-13$ & 126841 & \\
\hline 15 & Guideline & 44705 & Pub Type \\
\hline 16 & Guideline & 890174 & All Fields \\
\hline 17 & Guideline & 91945 & Title Word \\
\hline 18 & Guideline* & 1352569 & All Fields \\
\hline 19 & Guideline* & 212119 & Title Word \\
\hline 20 & Guidelines as Topic & 123289 & $\mathrm{MeSH}$ \\
\hline 21 & Guidelines as Topic & 430912 & All Fields \\
\hline 22 & Guidelines as Topic & 4 & Title Word \\
\hline 23 & Guideline Adherence & 27474 & $\mathrm{MeSH}$ \\
\hline 24 & Guideline Adherence & 229105 & All Fields \\
\hline 25 & Guideline Adherence & 2078 & Title Word \\
\hline 26 & Practice Guideline & 26163 & Pub Type \\
\hline 27 & Practice Guideline & 431308 & All Fields \\
\hline 28 & Practice Guideline & 13998 & Title Word \\
\hline 29 & Practice Guidelines as Topic & 96644 & $\mathrm{MeSH}$ \\
\hline 30 & Practice Guidelines as Topic & 365202 & All Fields \\
\hline 31 & Practice Guidelines as Topic & 3 & Title Word \\
\hline 32 & Clinical Guideline & 62502 & All Fields \\
\hline 33 & Clinical Guideline & 7144 & Title Word \\
\hline 34 & Clinical Practice Guideline & 35330 & All Fields \\
\hline 35 & Clinical Practice Guideline & 8173 & Title Word \\
\hline 36 & Consensus & 10580 & $\mathrm{MeSH}$ \\
\hline 37 & Consensus & 440518 & All Fields \\
\hline 38 & Consensus & 63878 & Title Word \\
\hline 39 & Recommendation* & 718933 & All Fields \\
\hline 40 & Recommendation* & 102557 & Title Word \\
\hline 41 & Workshop & 727098 & All Fields \\
\hline 42 & Workshop & 51211 & Title Word \\
\hline 43 & $\mathrm{OR} / 15-42$ & 2746585 & \\
\hline 44 & 14 AND 43 & 8623 & \\
\hline
\end{tabular}

